\title{
Chelation ability of spironaphthoxazine with metal ions in silica gel
}

\author{
Hiromasa Nishikiori,* Katsuya Teshima, Tsuneo Fujii \\ Department of Environmental Science and Technology, Faculty of Engineering, Shinshu \\ University, 4-17-1 Wakasato, Nagano 380-8553, Japan
}

Corresponding author: Hiromasa Nishikiori

Tel: +81-26-269-5536

Fax: +81-26-269-5550

E-mail: nishiki@shinshu-u.ac.jp

Department of Environmental Science and Technology, Faculty of Engineering,

Shinshu University, Wakasato, Nagano 380-8553, Japan 


\section{Abstract}

Spironaphthoxazine (SNO) and three metal ions, $\mathrm{Mg}^{2+}, \mathrm{Zn}^{2+}$, and $\mathrm{Al}^{3+}$, were dispersed in silica gels by the sol-gel method. The chelation ability of SNO with the metal ions in silica gels was investigated by measuring the fluorescence spectra and was compared to that of 8-hydroxyquinoline (8-HQ) in ethanol and silica gels. A merocyanine-type isomer photoderived from SNO as well as 8-HQ easily formed complexes of the metal ions in the order of $\mathrm{Al}^{3+}, \mathrm{Zn}^{2+}$, and $\mathrm{Mg}^{2+}$ because the coordination ability of the metal ions to such ligands depended on their electron affinity. The changes in the fluorescence spectra of the silica gel samples during light irradiation were also investigated. The relative band intensity due to the intermediate species between the original SNO and the merocyanine species decreased and that of the complex increased with the UV irradiation time. The reverse process was observed during visible irradiation. The UV irradiation effects on the chelation of SNO and its photochromic property also depended on the electron affinity of the metal ions.

Keywords: Spironaphthoxazine; Chelation; Metal Complex; 8-Hydroxyquinoline; Silica Gel; Fluorescence 


\section{Introduction}

Organic metal chelate complexes attract much interest as functional materials because they play an important role in energy collection and conversion in plants $[1,2]$. Such materials are used for artificial photosynthesis and photoelectric conversion [3-5]. Also, they are used in photoluminescence and electroluminescence devices that utilize their photophysical properties [6,7]. We focused on photoinduced metal chelation materials as potential ion sensing and ion exchange materials. It has been reported that specific organic ligands formed metal chelates during light irradiation [8-11].

Spirooxazines (SOs) exhibit the well-known photochromic reaction of photoinduced interconversion between the original colorless form and the colored merocyanine (MC) form $[12,13] . \quad$ The MC is easily coordinated with specific metal ions, e.g., $\mathrm{Zn}^{2+}$, in solution and forms both fluorescent and non-fluorescent $\mathrm{MC}-\mathrm{M}^{\mathrm{n}+}$ complexes; the fluorescent complexes are stable to heat and visible light while the non-fluorescent complexes are unstable $[8,9]$.

We previously reported the details of the fluorescence and excitation spectra of spironaphthoxazine (SNO) in various solvents [14]. Two types of fluorescent intermediate species $\left(\mathrm{X}_{\mathrm{s}}\right.$ and $\left.\mathrm{X}_{\mathrm{h}}\right)$ occurred between $\mathrm{SNO}$ and $\mathrm{MC}$ by cleavage of the spiro $\mathrm{C}-\mathrm{O}$ bond, as shown by Scheme 1 [15-17]. In low-polar solvents, such as benzene, upon the excitation of SNO $\left(\mathrm{E}_{1}\right)$, the 390-nm fluorescence $\left(\mathrm{F}_{1}\right)$ was normally emitted from its excited state 
(SNO*). In aprotic polar solvents, such as acetonitrile, some of the SNO molecules were transformed into a non-planar, strongly solvated species $\left(\mathrm{X}_{\mathrm{s}}\right)$. The transition from species $\mathrm{X}_{\mathrm{s}}$ to $\mathrm{X}_{\mathrm{s}} *\left(\mathrm{E}_{2}\right)$ is followed by a $450-\mathrm{nm}$ fluorescent emission $\left(\mathrm{F}_{2}\right)$. In protic polar solvents, such as ethanol and water, some of the SNO molecules are normally excited to $\mathrm{SNO}^{*}\left(\mathrm{E}_{1}\right)$ to produce the hydrogen-bonded species $\left(\mathrm{X}_{\mathrm{h}}{ }^{*}\right)$ by the $\mathrm{C}-\mathrm{O}$ bond breakage in the excited states, followed by the $430-\mathrm{nm}$ fluorescent transition to $\mathrm{X}_{\mathrm{h}}\left(\mathrm{F}_{3}\right)$. The species $\mathrm{X}_{\mathrm{h}}$ was immediately transformed into $\mathrm{SNO}$ or $\mathrm{MC}$ in the ground state. The fluorescence of the $\mathrm{MC}-\mathrm{Zn}^{2+}$ complex is observed at around $540 \mathrm{~nm}$ by UV irradiation of SNO in aprotic polar solvents, such as acetone and acetonitrile, in the presence of $\mathrm{Zn}^{2+}[8,9,18,19]$. The $\mathrm{MC}-\mathrm{Zn}^{2+}$ complex was not observed in ethanol because the $\mathrm{MC}$ form was stabilized by hydrogen bonding to the solvent molecules [20].

\section{(Scheme 1)}

The sol-gel method enables us to prepare functional solid materials containing organic and/or organometallic compounds at room temperature. Many researchers have reported investigations of the photochromic behavior of SOs in systems involving the sol-gel-xerogel transitions [21-28]. Clarifying the microscopic change in such a system requires control of the photoreaction of the compounds. The microscopic properties are, however, very complex, in which the physicochemical properties were investigated by in-situ spectroscopic 
measurements using a molecular probe [29-35]. The elucidation of the formation and dissociation of the metal chelate of $\mathrm{MC}$ in such systems leads to creating novel photofunctional materials.

In our previous studies, we observed the fluorescence photochromic behavior, that is, the photoinduced interconversion between $\mathrm{X}_{\mathrm{s}}$ and the $\mathrm{MC}-\mathrm{Zn}^{2+}$ complex in the hydrophobic interlayers of montmorillonite clay modified by organic surfactants [15] and in a xerogel prepared from silicon alkoxide [16,17]. The xerogel system also contained the MC-SiOH complex like the MC- $\mathrm{Zn}^{2+}$ because there were many $\mathrm{SiOH}$ groups on the surface of the gel pores in which the organic molecules were encapsulated $[16,17,21,23,26,30]$. The complex formation properties are expected to depend on the type of metal ions involving a specific electron affinity.

In this study, we investigated the chelation ability of SNO with three metal ions, $\mathrm{Mg}^{2+}, \mathrm{Zn}^{2+}$, and $\mathrm{Al}^{3+}$, in silica gels by measuring the fluorescence spectra in order to clarify the coordination interaction between the photoderived MC and metal ions. They were compared with that of a typical ligand, 8-hydroxyquinoline (8-HQ), in ethanol and silica gels because the metal ions can be coordinated to the nitrogen and oxygen atoms of MC as well as 8-HQ [36-39]. Scheme 2 illustrates the metal chelation of 8-HQ.

(Scheme 2) 


\section{Experimental section}

SNO was synthesized and purified according to a procedure described elsewhere [40]. 8-HQ (S grade), purchased from Wako Pure Chemicals, was used after recrystallization from an aqueous ethanol solution. Ethanol (S grade), tetraethylorthosilicate (TEOS) (S grade), magnesium chloride (S grade), zinc chloride ( $\mathrm{S}$ grade), aluminum chloride (S grade), and 5.0 mol $\mathrm{dm}^{-3}$ hydrochloric acid (for volumetric analysis), purchased from Wako Pure Chemicals, were used without further purification. Deionized and distilled water was used for preparing the solutions.

Ethanol solutions of 8-HQ with and without a metal chloride (magnesium chloride, zinc chloride, or aluminum chloride) were prepared in order to examine their complex formation properties, in which the concentration ranges of 8 -HQ and the metal chloride were $1.0 \times$ $10^{-5}-4.0 \times 10^{-3}$ and $1.0 \times 10^{-3}-9.0 \times 10^{-3} \mathrm{~mol} \mathrm{dm}^{-3}$, respectively. The UV-vis absorption and fluorescence spectra of the solutions were observed in optical quartz cells in which the light-path length was $1 \mathrm{~cm}$ using a Shimadzu UV-2500 spectrophotometer and a Shimadzu RF-5300PC fluorescence spectrophotometer, respectively.

The sol-gel reaction systems of TEOS were prepared in the following compositions: The

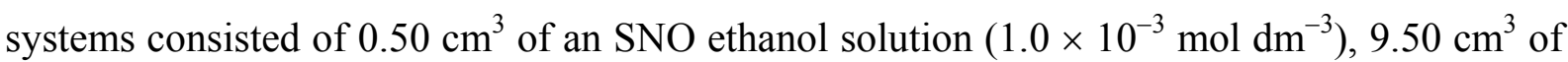


a metal chloride ethanol solution $\left(0,5.26 \times 10^{-5}, 5.26 \times 10^{-4}\right.$, or $\left.5.26 \times 10^{-3} \mathrm{~mol} \mathrm{dm}^{-3}\right), 10.0$ $\mathrm{cm}^{3}$ of TEOS, and $3.30 \mathrm{~cm}^{3}$ of hydrochloric acid $\left(1.0 \times 10^{-5} \mathrm{~mol} \mathrm{dm}^{-3}\right)$. The molar ratios of SNO to $\mathrm{M}(\mathrm{Mg}, \mathrm{Zn}$, or $\mathrm{Al})$ included in these solutions were 1/0,1/1, 1/10, and 1/100. The 8-HQ-containing sol-gel reaction systems of TEOS were also prepared in the same way. The molar ratios of 8-HQ to $\mathrm{M}(\mathrm{Mg}, \mathrm{Zn}$, or $\mathrm{Al})$ included in these solutions were $1 / 100$.

Each solution was stirred for 5 min using a magnetic stirrer and then allowed to react at 333 K. The UV-vis absorption spectra and fluorescence and excitation spectra were measured as a function of time along with the sol-gel-xerogel transitions using a Shimadzu UV-2500 spectrophotometer and a Shimadzu RF-5300 fluorescence spectrophotometer, respectively. After the xerogel formation of the samples (40 days), the changes in the fluorescence spectra by $\mathrm{UV}\left(350 \pm 10 \mathrm{~nm}, 21 \mathrm{~mW} \mathrm{~cm}^{-2}\right)$ and visible $\left(450 \pm 10 \mathrm{~nm}, 29 \mathrm{~mW} \mathrm{~cm}{ }^{-2}\right)$ light irradiation were observed in order to study the photochromic behavior. The lights for fluorescence observation and photoreaction trigger were obtained from the fluorescence spectrophotometer. The fluorescence was observed at incident and collecting angles of ca. $45^{\circ}$ on the front face of the xerogel sample. The absorption, i.e., transmission, spectral changes were difficult to observe in this study because the photoreaction occurred at the narrow and shallow surface part of the sample into which the light penetrated. The irradiated light can be calculated to penetrate into ca. a $0.5 \mathrm{~mm}$ depth of the sample. On the other hand, the fluorescence 
measurement is more sensitive to the structural changes in the species than the absorption measurement and can effectively allow to observe the reaction at the sample surface. We mainly observed the relative amount changes in the fluorescent species by fluorescence spectroscopy and then analyzed the photoreaction.

\section{Results and discussion}

\subsection{Chelation of SNO with metal ions}

Fig. 1 shows the UV-vis absorption and fluorescence spectra of the sol-gel reaction systems containing $\mathrm{SNO}$ and $\mathrm{Al}^{3+}(\mathrm{SNO} / \mathrm{Al}=1 / 10)$ observed as a function of time after their preparation. The gelation of this system occurred at about 1 day. Absorption bands at 300-380 and 380-500 $\mathrm{nm}$ are mainly assigned to $\mathrm{SNO}$ and the $\mathrm{MC}-\mathrm{Al}^{3+}$ complex, respectively. The band intensity of the $\mathrm{MC}-\mathrm{Al}^{3+}$ complex increased with the progress of the sol-gel reaction. The increase in the shorter wavelength band was caused by light scattering from the xerogel. Fluorescence peaks at around 450 and $540 \mathrm{~nm}$ are assigned to the intermediate species, $\mathrm{X}$, and the $\mathrm{MC}-\mathrm{Al}^{3+}$ complex, respectively. SNO exhibits weak fluorescence. $\mathrm{X}$, corresponding to $\mathrm{X}_{\mathrm{h}}$ observed in protic polar solvents [14], and $\mathrm{MC}-\mathrm{Al}^{3+}$ are the main fluorescent species in the sol just after the preparation ( 0 day). The absorption band of X was hidden by that of SNO. As the reaction further proceeded after the gelation, 
the species was strongly encapsulated by the gel matrix and transformed into the species corresponding to $\mathrm{X}_{\mathrm{s}}$ because the dehydrated condensation of the $\mathrm{SiOH}$ groups proceeded to form the -SiOSi- networks, accompanied by weakening of their hydrogen bonding. These phenomena were confirmed by the excitation spectra as previously clarified in the $\mathrm{Zn}^{2+}$-containing systems [16]. The complex was formed even just after the preparation of the $\mathrm{Al}^{3+}$-containing system and then increased in its amount relative to $\mathrm{X} . \quad$ In the previous study, $\mathrm{MC}-\mathrm{Al}^{3+}$ was formed in the ethanol solution containing $\mathrm{Al}^{3+}$ even in the dark, whereas no complex was observed in the solution containing $\mathrm{Mg}^{2+}$ or $\mathrm{Zn}^{2+}$ even during UV irradiation [20]. Certain amounts of $\mathrm{MC}-\mathrm{Mg}^{2+}$ and $\mathrm{MC}-\mathrm{Zn}^{2+}$ were formed in the present sol-gel reaction systems. The relative amount of the complex was greater than those in the gel containing $\mathrm{Mg}^{2+}$ or $\mathrm{Zn}^{2+}$. The peak wavelengths for $\mathrm{X}$ and $\mathrm{MC}-\mathrm{Al}^{3+}$ were shifted by the change in the microenvironment of the system.

(Fig. 1)

Fig. 2 shows the UV-vis absorption and fluorescence spectra of the xerogels containing $\mathrm{SNO}$ and $\mathrm{Al}^{3+}$ observed as a function of the amount of $\mathrm{Al}^{3+}$. The absorption and fluorescence peaks assigned to the complex were observed at around 450 and $540 \mathrm{~nm}$, respectively, even in the Al-free gel. This can be assigned to the complex of MC and the $\mathrm{SiOH}$ group because the proton can form a weak bridge between the oxygen and nitrogen 
atoms like the $\mathrm{MC}-\mathrm{Al}^{3+}$ complex as previously revealed [16]. The relative intensities of the complex peaks increased with an increase in the Al amount.

(Fig. 2)

Fig. 3 shows a comparison of the UV-vis absorption and fluorescence spectra of the xerogels containing $\mathrm{SNO}$ with no metal $\left(\mathrm{H}^{+}\right.$from $\mathrm{SiOH}$ group), $\mathrm{Mg}^{2+}, \mathrm{Zn}^{2+}$, and $\mathrm{Al}^{3+}(\mathrm{SNO} / \mathrm{M}$ $=1 / 10$ ). The absorbance and fluorescence intensity of the complex relative to those of $\mathrm{X}$ were higher in the order of $\mathrm{Al}^{3+}, \mathrm{Zn}^{2+}, \mathrm{Mg}^{2+}$, and no metal $\left(\mathrm{H}^{+}\right)$. This indicates the chelation abilities of SNO with the metal ions because the ionization energy values to produce $\mathrm{Al}^{3+}, \mathrm{Zn}^{2+}$, and $\mathrm{Mg}^{2+}$, i.e., their electron affinity, are $28.4,18.0$, and $15.0 \mathrm{eV}$, respectively [41]. The electron affinity determines the electrophilicity of the metal ions for the electron pairs on the oxygen and nitrogen of the MC species. However, the estimated ability is not accurate because the extinction coefficients and fluorescence quantum efficiency of $\mathrm{MC}-\mathrm{M}^{\mathrm{n}+}$ are unknown. It is very difficult to obtain these values in the sol-gel reaction systems because the shape and volume of the samples and concentration of the contents are hard to control. Also, the xerogel samples absorb and scatter UV light. These factors cause difficulty in determining the quantitative spectroscopic properties. On the other hand, the chelation ability of $\mathrm{MC}$ with three metal ions, $\mathrm{Mg}^{2+}, \mathrm{Zn}^{2+}$, and $\mathrm{Al}^{3+}$, in ethanol cannot be compared 
numerically because $\mathrm{MC}-\mathrm{M}^{\mathrm{n}+}$ was formed in the ethanol solution containing $\mathrm{Al}^{3+}$ but was not formed in the solution containing $\mathrm{Mg}^{2+}$ or $\mathrm{Zn}^{2+}[20]$.

(Fig. 3)

\subsection{Chelation of 8-HQ with metal ions}

In order to discuss the coordination ability of the metal ions with $\mathrm{SNO}$, one of the well-known ligands, 8-hydroxyquinoline (8-HQ), was used for investigation of the metal chelation in ethanol solutions [36-39]. 8-HQ forms the metal complex, $\mathrm{Q}^{-}-\mathrm{M}^{\mathrm{n}+}$, in the ethanol solutions as follows:

$$
\begin{aligned}
& \mathrm{Q}^{-}+\mathrm{M}^{\mathrm{n}+} \stackrel{K}{\rightleftarrows} \mathrm{Q}^{-}-\mathrm{M}^{\mathrm{n}+} \\
& K=\left[\mathrm{Q}^{-}-\mathrm{M}^{\mathrm{n}+}\right] /\left[\mathrm{Q}^{-}\right]\left[\mathrm{M}^{\mathrm{n}+}\right]
\end{aligned}
$$

where $\mathrm{Q}^{-}$and $K$ are the quinolate and the complex formation constant, respectively. The ratio of $\mathrm{Q}^{-}$to the metal ion should be $1 / 1$ because the metal concentration was much higher than that of 8 -HQ in this study. The $K$ and molar extinction coefficient $\mathrm{Q}^{-}-\mathrm{M}^{\mathrm{n}+}$ at its absorption maximum, $\varepsilon_{\mathrm{Q}-\mathrm{M}}$, can be estimated by the Rose-Drago plot using the following equation, in which the $\mathrm{Q}^{-}$or $\mathrm{M}^{\mathrm{n}+}$ does not exhibit any absorption [42]:

$$
1 / K=A / \varepsilon_{\mathrm{Q}-\mathrm{M}}-\left[\mathrm{Q}^{-}\right]_{0}-\left[\mathrm{M}^{\mathrm{n}+}\right]_{0}+\left[\mathrm{Q}^{-}\right]_{0}\left[\mathrm{M}^{\mathrm{n}+}\right]_{0} \varepsilon_{\mathrm{Q}-\mathrm{M}} / A
$$

where $A$ is the maximum absorbance of the solution containing 8-HQ and a metal ion. This equation provides various sets of $1 / K$ and $\varepsilon_{\mathrm{Q}-\mathrm{M}}$ values for a given set of experimental data, i.e., 
the initial concentrations of $\mathrm{Q}^{-}\left(\left[\mathrm{Q}^{-}\right]_{0}\right)$ and $\mathrm{M}^{\mathrm{n}+}\left(\left[\mathrm{M}^{\mathrm{n}+}\right]_{0}\right)$. The absorption maxima of $8-\mathrm{HQ}$, $\mathrm{Q}^{-}-\mathrm{Mg}^{2+}, \mathrm{Q}^{-}-\mathrm{Zn}^{2+}$, and $\mathrm{Q}^{-}-\mathrm{Al}^{3+}$ in ethanol were $315,370,380$, and $370 \mathrm{~nm}$, respectively (supporting information, Fig. S1). The relationships between $1 / K$ and $\varepsilon_{\mathrm{Q}-\mathrm{M}}$ under specific conditions are plotted in Fig. 4. The values of $K$ and $\varepsilon_{\mathrm{Q}-\mathrm{M}}$ were obtained from the values at the point of intersection.

(Fig. 4)

The molar fluorescence intensity of the complex should be considered for its quantitative discussion. The fluorescence spectra of 8-HQ and $\mathrm{Q}^{-}-\mathrm{M}^{\mathrm{n}+}$ were measured upon $342 \mathrm{~nm}$ excitation, which was the isosbestic point in their absorption spectra. Fig. 5 shows the concentration dependence of fluorescence spectra and intensities of these species. The fluorescence maxima of 8-HQ, $\mathrm{Q}^{-}-\mathrm{Mg}^{2+}, \mathrm{Q}^{-}-\mathrm{Zn}^{2+}$, and $\mathrm{Q}^{-}-\mathrm{Al}^{3+}$ in ethanol were 408, 526, 560, and $510 \mathrm{~nm}$, respectively. The fluorescence intensity ratio of $\mathrm{Q}^{-}-\mathrm{M}^{\mathrm{n}+}$ to $\mathrm{Q}^{-}$is written as:

$$
I_{\mathrm{Q}-\mathrm{M}} / I_{\mathrm{Q}}=\left[\mathrm{Q}^{-}-\mathrm{M}^{\mathrm{n}+}\right] /\left[\mathrm{Q}^{-}\right] \times \varepsilon_{\mathrm{Q}-\mathrm{M}} / \varepsilon_{\mathrm{Q}} \times \Phi_{\mathrm{Q}-\mathrm{M}} / \Phi_{\mathrm{Q}}
$$

where $I, \varepsilon$, and $\Phi$ are the fluorescence intensity, molar extinction coefficient, and fluorescence quantum efficiency of the subscript species, respectively. In this case, $\varepsilon_{\mathrm{Q}-\mathrm{M}}$ is equal to $\varepsilon_{\mathrm{Q}}$ at the isosbestic point. The molar fluorescence intensities of $\mathrm{Q}^{-}-\mathrm{M}^{\mathrm{n}+}$ and 8-HQ in ethanol were estimated by investigation of the influences of their concentration on the fluorescence intensity as shown in Fig. 5. This led to the fluorescence quantum efficiency ratio of 
$\mathrm{Q}^{-}-\mathrm{M}^{\mathrm{n}+}$ to $8-\mathrm{HQ}$. The resulting physicochemical constants are shown in Table 1. The complex formation constants of $\mathrm{Q}^{-}-\mathrm{M}^{\mathrm{n}+}$ were higher in the order of $\mathrm{M}^{\mathrm{n}+}=\mathrm{Zn}^{2+}, \mathrm{Al}^{3+}$, and $\mathrm{Mg}^{2+}$, which was different from the order of their electron affinity. This is because the complex formation process of $8-\mathrm{HQ}$ with $\mathrm{Al}^{3+}$ is not simple, i.e., the aluminum ion involving a high electron affinity forms multinuclear complexes with ethanol molecules [37].

(Fig. 5 and Table 1)

8-HQ was incorporated in the gels in order to discuss the coordination ability of the metal ions in them. Fig. 6 shows the UV-vis absorption and fluorescence spectra of the xerogels containing 8-HQ with $\mathrm{Mg}^{2+}, \mathrm{Zn}^{2+}$, or $\mathrm{Al}^{3+}$. The excitation wavelength was $342 \mathrm{~nm}$, which was the isosbestic point in the absorption spectra of $8-\mathrm{HQ}$ and $\mathrm{Q}^{-}-\mathrm{M}^{\mathrm{n}+}$ in ethanol. The absorption and fluorescence maxima were almost the same values as those in ethanol. The fluorescence intensity of the complex was higher in the order of $\mathrm{Al}^{3+}, \mathrm{Zn}^{2+}$, and $\mathrm{Mg}^{2+}$. It is difficult to obtain the molar extinction coefficient and fluorescence quantum efficiency values of the species in the xerogels. The relative intensities of 8-HQ were lower than those observed upon excitation at a wavelength shorter than $342 \mathrm{~nm}$, whereas those of the complexes were lower than those observed upon excitation at a wavelength longer than 342 $\mathrm{nm}$ (supporting information, Fig. S2). The molar ratio of $\mathrm{Q}^{-}-\mathrm{M}^{\mathrm{n}+}$ to $\mathrm{Q}^{-}$was estimated by the above equation assuming that these values are relatively equal to those observed in 
ethanol. Consequently, the coordination ability was higher in the same order, which corresponded to that of their electron affinity. The fluorescence properties of $\mathrm{Q}^{-}-\mathrm{M}^{\mathrm{n}+}$ are shown in Table 2.

(Fig. 6 and Table 2)

3.3. Photochromic reaction between SNO and metal ions

The UV-vis absorption spectra of the xerogel containing SNO and $\mathrm{M}^{\mathrm{n}+}$ were measured as a function of the UV irradiation time. A slight spectral change was observed because the photoreaction occurred at the narrow and shallow surface part of the sample into which the light penetrated. Fig. 7 shows the difference UV-vis absorption spectra between the original spectra of the silica xerogel containing SNO and $\mathrm{Zn}^{2+}(\mathrm{SNO} / \mathrm{Zn}=1 / 10)$ and those observed after 240-min UV and 480-min visible irradiation. The positive and negative values denote the increase and decrease in the absorbance, respectively. The absorption bonds at $330-380$ and $400-500 \mathrm{~nm}$ are assigned to $\mathrm{SNO}$ or $\mathrm{X}$ and $\mathrm{MC}-\mathrm{Zn}^{2+}$, respectively The photoreaction in the xerogel samples was investigated by fluorescence spectroscopy.

(Fig. 7)

Figs. 8 and 9 show the changes in the fluorescence and excitation spectra of the xerogel containing SNO and $\mathrm{Zn}^{2+}(\mathrm{SNO} / \mathrm{Zn}=1 / 10)$ observed as a function of the $\mathrm{UV}$ irradiation time. In the fluorescence spectra, the relative intensity of the $\mathrm{X}$ band decreased and that of the 
complex band increased with the irradiation time. The excitation peak at $350-400 \mathrm{~nm}$ is assigned to $\mathrm{X}$ and those at $300-350$ and $400-500 \mathrm{~nm}$ are assigned to $\mathrm{MC}-\mathrm{Zn}^{2+}[16,17]$. The excitation spectrum's changes support the results of the fluorescence spectral measurement. Figs. 10 and 11 show the changes in the fluorescence and excitation spectra of the above samples observed as a function of the visible irradiation. The reverse process was observed during the visible irradiation. This behavior corresponded to the results reported in previous papers $[16,17]$. The increase and decrease in the band intensities were similar to those observed in the gels containing $\mathrm{Mg}^{2+}$ and $\mathrm{Al}^{3+}$. The formation of the $\mathrm{MC}-\mathrm{M}^{\mathrm{n}+}$ complex in solvents and the sol-gel matrices was found to be a quasi first-order reaction in previous studies $[8,16,22,23,25]$. The changes in the fluorescence intensities of $\mathrm{X}$ and the $\mathrm{MC}-\mathrm{M}^{\mathrm{n}+} / \mathrm{MC}-\mathrm{SiOH}$ complexes were analyzed versus the irradiation time of the UV and visible light using the quasi first-order and second-order reaction models.

(Figs. 8, 9, 10, and 11)

Fig. 12 shows the time course of the fluorescence intensities of the complex in the xerogels containing SNO with no metal $\left(\mathrm{H}^{+}\right), \mathrm{Mg}^{2+}, \mathrm{Zn}^{2+}$, and $\mathrm{Al}^{3+}(\mathrm{SNO} / \mathrm{M}=1 / 10)$. Certain fluorescence intensities of $\mathrm{X}$ and $\mathrm{MC}-\mathrm{M}^{\mathrm{n}+}$ were observed in the samples with $\mathrm{SNO} / \mathrm{M}=1 / 10$. The fluorescence measurements provide the relative changes in the amount of the species and their reaction kinetics. The complex formation and dissociation reactions reach their 
photostationary state after a certain extent of irradiation. These changes were well fitted to the quasi first-order reaction model according to the $\chi^{2}$ values. The resulting apparent rate constants are shown in Table 3. The complex formation rate constants were higher in the order of the coordination ability of the metal ions. The dissociation constants for the complex were almost the same values. This indicates that the dissociation depended on the molecular and electronic structure in the excited states of the ligand rather than the electron affinity of the metal ions.

(Fig. 12 and Table 3)

The MC is easily coordinated with specific metal ions in the solvents and forms a fluorescent chelate complex. It is difficult to dissociate the complex in solvents because it is stable to heat and visible light. The reversible photochromic reaction requires controlling the interaction between the SNO molecule and metal ion. MC formed reversible complexes with metal bonding to the oxide networks of the silica gel and the complexes were dissociated by visible irradiation because the MC was weakly coordinated to the metal depending on its electron affinity or electrophilicity.

\section{Conclusions}

The chelation ability of SNO to three metal ions, $\mathrm{Mg}^{2+}, \mathrm{Zn}^{2+}$, and $\mathrm{Al}^{3+}$, in silica gels was 
investigated by measuring the fluorescence spectra in order to clarify the coordination interaction between the photoderived MC and the metal ions. They were compared to that of a typical ligand, 8-HQ, in ethanol and silica gels. $\quad$ 8-HQ more easily formed the metal complex, $\mathrm{Q}^{-}-\mathrm{M}^{\mathrm{n}+}$, with a metal ion involving a higher electron affinity in the silica gels. SNO more easily formed the complexes with the metal ions with which 8-HQ more easily formed the complexes. SNO exhibited a photochromic interconversion between the $\mathrm{X}$ and $\mathrm{MC}^{\mathrm{M}} \mathrm{M}^{\mathrm{n}}$ species in the silica gels by UV and visible irradiation. The complex formation rate of the $\mathrm{X}$ depended on the coordination ability of the metal ions, whereas the dissociation depended on the molecular and electronic structures in the excited states of the ligand rather than the electron affinity of the metal ions. MC formed reversible complexes with metal bonding to the oxide networks of the silica gel, and the complexes were dissociated by visible irradiation because the MC was weakly coordinated to the metal.

\section{References}

[1] H. Tamiaki, R. Shibata, T. Mizoguchi, Photochem. Photobiol. 83 (2007) 152-162.

[2] R. J. Cogdell, A. T. Gardiner, A. W. Roszak, C. J. Law, J. Southall, N. W. Isaacs, Photosynth. Res. 81 (2004) 207-214.

[3] G. Steinberg-Yfrach, J. L. Rigaud, E. N. Durantini, A. L. Moore, D. Gust, T. A. Moore, 
Nature 392 (1998) 479-482.

[4] M. Nagata, Y. Nakamura, E. Nishimura, K. Nakagawa, Y. Suemori, K. Iida, M. Nango, Trans. MRS-J 30 (2005) 655-658.

[5] Y. Amao, CHEMCATCHEM 3 (2011) 458-474.

[6] M. A. Baldo, D. F. O’Brien, Y. You, A. Shoustikov, S. Sibley M. E. Thompson, S. R. Forrest, Nature 395 (1998) 151-154.

[7] N. Ohtani, N. Kitagawa, T. Matsuda, Jpn. J. Appl. Phys. 50 (2011) 01 BC08.

[8] J. Zhou, F. Zhou, Y. Li, F. Zhang, X. Song, J. Photochem. Photobiol. A: Chem. 92 (1995) 193-199.

[9] M. J. Preigh, F. Lin, K. Z. Ismail, S. G. Weber, J. Chem. Soc., Chem. Commun. (1995) 2091-2092.

[10] H. Görner, A. K. Chibisov, J. Chem. Soc., Faraday Trans. 94 (1998) 2557-2564.

[11] S. Kumar, D. Hernandez, B. Hoa, Y. Lee, J. S. Yang, A. McCurdy, Org. Lett. 10 (2008) 3761-3764.

[12] G. Berkovic, V. Krongauz, V. Welss, Chem. Rev. 100 (2000) 1741-1753.

[13] W. Yuan, L. Sun, H. Tang, Y. Wen, G. Jiang, W. Huang, L. Jiang, Y. Song, H. Tian, D. Zhu, Adv. Mater. 17 (2005) 156-160.

[14] H. Nishikiori, N. Tanaka, K. Takagi, T. Fujii, Res. Chem. Intermed. 29 (2003) 485-493. 
[15] H. Nishikiori, R. Sasai, K. Takagi, T. Fujii, Langmuir 22 (2006) 3376-3380.

[16] H. Nishikiori, N. Tanaka, K. Takagi, T. Fujii, J. Photochem. Photobiol. A: Chem. 183 (2006) 53-58.

[17] H. Nishikiori, N. Tanaka, K. Takagi, T. Fujii, J. Photochem. Photobiol. A: Chem. 189 (2007) 46-54.

[18] S. H. Kim, S. Wang, C. H. Ahn, M. S. Choi, Fibers Polymers 8 (2007) 447-449.

[19] Z. Tian, R. A. Stairs, M. Wyer, N. Mosey, J. M. Dust, T. M. Kraft, E. Buncel, J. Phys. Chem. A 114 (2010) 11900-11909.

[20] H. Nishikiori, T. Takamura, S. Shimamura, T. Fujii, J. Photochem. Photobiol. A: Chem. 222 (2011) 236-240.

[21] J. Biteau, F. Chaput, J. -P. Boilot, J. Phys. Chem. 100 (1996) 9024-9031.

[22] L. Hou, H. Schmidt, J. Mater. Sci. 31 (1996) 3427-3434.

[23] X. Sun, M. Fan, E. T. Knobbe, Mol. Cryst. Liq. Cryst. 297 (1997) 57-64.

[24] B. Schaudel, C. Guermeur, C. Sanchez, K. Nakatani, J. A. Delaire, J. Mater. Chem. 7 (1997) 61-65.

[25] F. Ortica, G. Favaro, J. phys. Chem. B 104 (2000) 12179-12183.

[26] A. Lafuma, S. Chodorowski-Kimmes, F. X. Quinn, C. Sanchez, Eur. J. Inorg. Chem. (2003) 331-338. 
[27] R. Pardo, M. Zayat, D. Levy, J. Photochem. Photobiol. A: Chem. 198 (2008) 232-236.

[28] C. W. Kim, S. W. Oh, Y. H. Kim, H. G. Cha, Y. S. Kang, J. Phys. Chem. C 112 (2008) $1140-1145$.

[29] R. Winter, D. W. Hua, X. Song, W. Mantulin, J. Jonas, J. Phys. Chem. 94 (1990) 2706-2713.

[30] T. Fujii, T. Mabuchi, H. Kitamura, O. Kawauchi, N. Negishi, M. Anpo, Bull. Chem. Soc. Jpn. 65 (1992) 720-727.

[31] T. Fujii, K. Toriumi, J. Chem. Soc. Faraday Trans. 89 (1993) 3437-3441.

[32] U. Narang, R. Wang, P. N. Prasad, F. V. Bright, J. Phys. Chem. 98 (1994) 17-22.

[33] K. Matsui, K. Nozawa, Bull. Chem. Soc. Jpn. 70 (1997) 2331-2335.

[34] B. Dunn, J. I. Zink, Chem. Mater. 9 (1997) 2280-2291.

[35] T. Mabuchi, H. Nishikiori, N. Tanaka, T. Fujii, J. Sol-Gel Sci. Technol. 33 (2005) $333-340$.

[36] W. D. Johnston, H. Freiser, J. Am. Chem. Soc. 74 (1952) 5239-5242.

[37] W. E. Ohnesorge, J. Inorg. Nucl. Chem. 29 (1967) 485-493.

[38] A. V. Karyakin, T. S. Sorokina, L. I. Anikina, T. G. Akimova, M. G. Ezernitskaya, Doklady Phys. Chem., Translation Phys. Chem. Sect. Doklady Akad. Nauk SSSR 241 (1979) 667-669. 
[39] Y. Onoue, K. Hiraki, K. Morishige, Y. Nishizawa, Nippon Kagaku Kaishi 1978 (1978) 1237-1243 (in Japanese).

[40] N. Y. C. Chu, in: H. Dürr, H. Bouas-Laurent (Eds.), Photochromism: Molecules and Systems, Elsevier, Amsterdum, 2003, pp. 506-507.

[41] D. R. Lide (Ed.), CRC Handbook of Chemistry and Physics, 85th Edtion, CRC Press, Boca Raton, 2004, pp.10-183-10-184.

[42] N. J. Rose, R. S. Drago, J. Am. Chem. Soc. 81 (1959) 6138-6141. 
Table 1 Physicochemical properties of $\mathrm{Q}^{-}-\mathrm{M}^{\mathrm{n}+}$ in ethanol.

\begin{tabular}{cccc}
\hline $\mathrm{M}$ & $K / \mathrm{mol}^{-1} \mathrm{dm}^{3}$ & $\varepsilon_{\max } / \mathrm{dm}^{3} \mathrm{~cm}^{-1} \mathrm{~mol}^{-1}$ & $\Phi_{\mathrm{Q}-\mathrm{M}} / \Phi_{\mathrm{Q}}$ \\
\hline $\mathrm{Mg}^{2+}$ & $1580 \pm 30$ & $704 \pm 1$ & 120 \\
$\mathrm{Zn}^{2+}$ & $4880 \pm 120$ & $2328 \pm 2$ & 123 \\
$\mathrm{Al}^{3+}$ & $2740 \pm 40$ & $2154 \pm 2$ & 547 \\
\hline
\end{tabular}

$K$ : complex formation constant

Table 2 Fluorescence properties of $\mathrm{Q}^{-}-\mathrm{M}^{\mathrm{n}+}$ in the silica gel.

\begin{tabular}{ccc}
\hline $\mathrm{M}$ & $I_{\mathrm{Q}-\mathrm{M}} / I_{\mathrm{Q}}$ & {$[\mathrm{Q}-\mathrm{M}] /[\mathrm{Q}]$} \\
\hline $\mathrm{Mg}^{2+}$ & $4.66 \pm 0.65$ & $0.039 \pm 0.005$ \\
$\mathrm{Zn}^{2+}$ & $14.9 \pm 3.3$ & $0.121 \pm 0.027$ \\
$\mathrm{Al}^{3+}$ & $330 \pm 22$ & $0.604 \pm 0.039$ \\
\hline
\end{tabular}

Table 3 Apparent complex formation and dissociation constants (first-order and second-order) of SNO in the silica gel.

\begin{tabular}{ccc}
\hline & \multicolumn{2}{c}{ Rate constant $/ 10^{-3} \mathrm{~min}^{-1}$ (first-order) } \\
\cline { 2 - 3 } & \multicolumn{1}{c}{ Formation $\left(\chi^{2}\right)$} & Dissociation $\left(\chi^{2}\right)$ \\
\hline $\left.\mathrm{H}^{+}\right)$ & $9.8 \pm 0.5(0.25)$ & $3.0 \pm 0.8(0.079)$ \\
$\mathrm{Mg}^{2+}$ & $19.6 \pm 1.2(0.25)$ & $2.9 \pm 1.2(0.49)$ \\
$\mathrm{Zn}^{2+}$ & $25.9 \pm 1.5(0.016)$ & $3.7 \pm 0.5(0.062)$ \\
$\mathrm{Al}^{3+}$ & $94.7 \pm 9.8(0.0013)$ & $3.4 \pm 0.9(0.088)$ \\
\hline & Rate constant $/ \mathrm{mol}^{-1} \mathrm{dm}^{3} \min ^{-1}($ second-order $)$ \\
\cline { 2 - 3 } $\mathrm{M}^{2}$ & Formation $\left(\chi^{2}\right)$ & Dissociation $\left(\chi^{2}\right)$ \\
\hline $\left.\mathrm{H}^{+}\right)$ & $(7.2 \pm 1.8) \times 10^{-5}(0.39)$ & $(1.6 \pm 0.8) \times 10^{-5}(0.077)$ \\
$\mathrm{Mg}^{2+}$ & $(2.7 \pm 0.4) \times 10^{-4}(0.40)$ & $(1.5 \pm 0.9) \times 10^{-5}(0.49)$ \\
$\mathrm{Zn}^{2+}$ & $(5.1 \pm 1.8) \times 10^{-4}(0.074)$ & $(1.2 \pm 0.1) \times 10^{-5}(0.069)$ \\
$\mathrm{Al}^{3+}$ & $(1.7 \pm 0.3) \times 10^{-2}(0.0021)$ & $(2.0 \pm 1.0) \times 10^{-5}(0.088)$ \\
\hline
\end{tabular}




\section{Scheme titles and figure captions}

Scheme 1 Isomerization and metal chelation of SNO and fluorescence processes of SNO isomers in solvents.

Scheme 2 Metal chelation of 8-HQ.

Figure 1 (a) UV-vis absorption and (b) fluorescence spectra of the sol-gel reaction systems containing $\mathrm{SNO}$ and $\mathrm{Al}^{3+}(\mathrm{SNO} / \mathrm{Al}=1 / 10)$ observed as a function of time after their preparation. The excitation wavelength was $350 \mathrm{~nm}$.

Figure 2 (a) UV-vis absorption and (b) fluorescence spectra of the silica xerogels containing $\mathrm{SNO}$ and $\mathrm{Al}^{3+}$ observed as a function of the amount of $\mathrm{Al}^{3+}$. The excitation wavelength was $350 \mathrm{~nm}$.

Figure 3 (a) UV-vis absorption and (b) fluorescence spectra of the silica xerogels containing SNO with no metal $\left(\mathrm{H}^{+}\right), \mathrm{Mg}^{2+}, \mathrm{Zn}^{2+}$, and $\mathrm{Al}^{3+}(\mathrm{SNO} / \mathrm{M}=1 / 10)$. The excitation wavelength was $350 \mathrm{~nm}$. 
Figure 4 Rose-Drago plots of 8-HQ ethanol solutions with (a) $\mathrm{Mg}^{2+}$, (b) $\mathrm{Zn}^{2+}$, and (c) $\mathrm{Al}^{3+}$ in which the concentration of 8-HQ was $1.0 \times 10^{-4} \mathrm{~mol} \mathrm{dm}^{-3}$ and those of metal ions were (1) $4.0 \times 10^{-3}$, (2) $6.0 \times 10^{-3}$, (3) $8.0 \times 10^{-3}$, and (4) $9.0 \times 10^{-3} \mathrm{~mol} \mathrm{dm}^{-3}$.

Figure 5 Concentration dependence of (a) fluorescence spectra and (b) intensities of 8-HQ $\left(\mathrm{H}^{+}\right)$and $\mathrm{Q}^{-}-\mathrm{M}^{\mathrm{n}+}\left(\mathrm{M}^{\mathrm{n}+}=\mathrm{Mg}^{2+}, \mathrm{Zn}^{2+}\right.$, and $\left.\mathrm{Al}^{3+}\right)$ in ethanol. The excitation wavelength was $342 \mathrm{~nm}$. The observation wavelengths were 408, 526, 560, and $510 \mathrm{~nm}$ for $\mathrm{H}^{+}, \mathrm{Mg}^{2+}, \mathrm{Zn}^{2+}$, and $\mathrm{Al}^{3+}$.

Figure 6 (a) UV-vis absorption and (b) fluorescence spectra of the silica xerogels containing 8-HQ with $\mathrm{Mg}^{2+}, \mathrm{Zn}^{2+}$, and $\mathrm{Al}^{3+}$. The excitation wavelength was $342 \mathrm{~nm}$.

Figure 7 Difference UV-vis absorption spectra between the original spectra of the silica xerogel containing SNO and $\mathrm{Zn}^{2+}(\mathrm{SNO} / \mathrm{Zn}=1 / 10)$ and those observed after (1) 240-min UV and (2) 480-min visible irradiations. 
Figure 8 Changes in the fluorescence spectra of the silica xerogel containing SNO and $\mathrm{Zn}^{2+}(\mathrm{SNO} / \mathrm{Zn}=1 / 10)$ observed as a function of the UV irradiation time. The excitation wavelengths were (a) 350 and (b) $450 \mathrm{~nm}$.

Figure 9 Changes in the fluorescence excitation spectra of the silica xerogel containing SNO and $\mathrm{Zn}^{2+}(\mathrm{SNO} / \mathrm{Zn}=1 / 10)$ observed as a function of the UV irradiation time. The observation wavelengths were (a) 450 and (b) $540 \mathrm{~nm}$.

Figure 10 Changes in the fluorescence spectra of the silica xerogel containing SNO and $\mathrm{Zn}^{2+}(\mathrm{SNO} / \mathrm{Zn}=1 / 10)$ observed as a function of the visible irradiation time. The excitation wavelengths were (a) 350 and (b) $450 \mathrm{~nm}$.

Figure 11 Changes in the fluorescence excitation spectra of the silica xerogel containing SNO and $\mathrm{Zn}^{2+}(\mathrm{SNO} / \mathrm{Zn}=1 / 10)$ observed as a function of the visible irradiation time. The observation wavelengths were (a) 450 and (b) $540 \mathrm{~nm}$. 
Figure 12 Time course of the fluorescence intensities of the complex in the silica xerogels containing SNO with no metal $\left(\mathrm{H}^{+}\right), \mathrm{Mg}^{2+}, \mathrm{Zn}^{2+}$, and $\mathrm{Al}^{3+}(\mathrm{SNO} / \mathrm{M}=1 / 10)$. The excitation and observation wavelengths were (a) 350 and $450 \mathrm{~nm}$, and (b) 450 and $540 \mathrm{~nm}$, respectively. 
Scheme 1
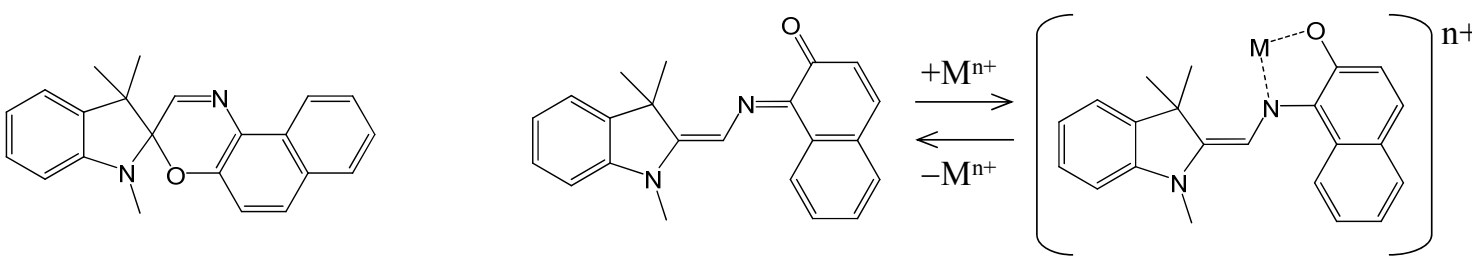

MC-M complex

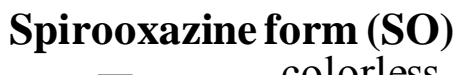

Merocyanine form (MC)<smiles>C1CC2CC1C2</smiles>
colorless

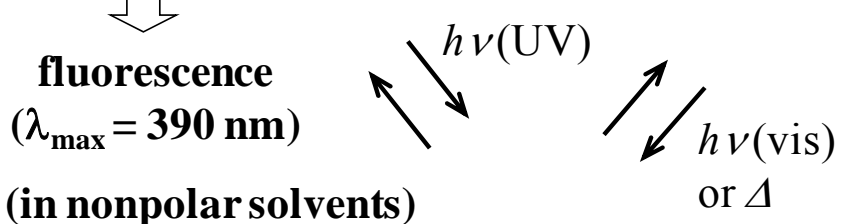

blue

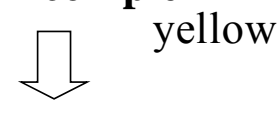

fluorescence

$\left(\lambda_{\max }=540 \mathrm{~nm}\right)$

(in nonpolar solvents)
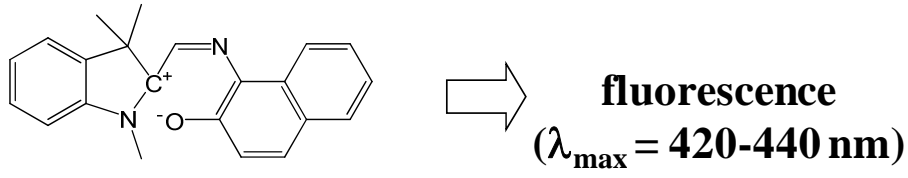

Intermediate species $\left(X_{s}\right.$ and $\left.X_{h}\right)$ (in polar solvents)

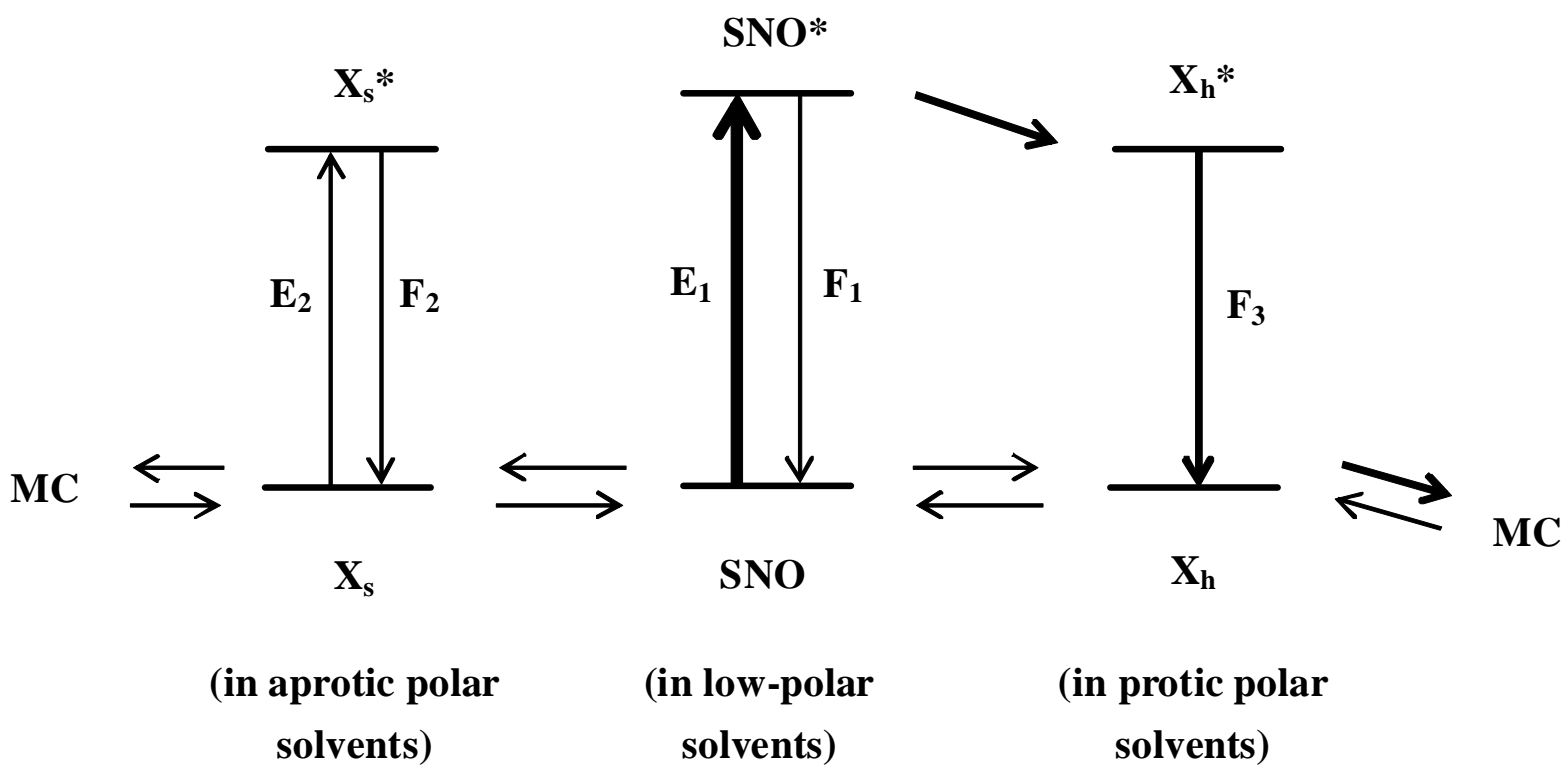


Scheme 2

$\underbrace{\longrightarrow}+\mathrm{M}^{\mathrm{n}+}$ 
Figure 1

(a)

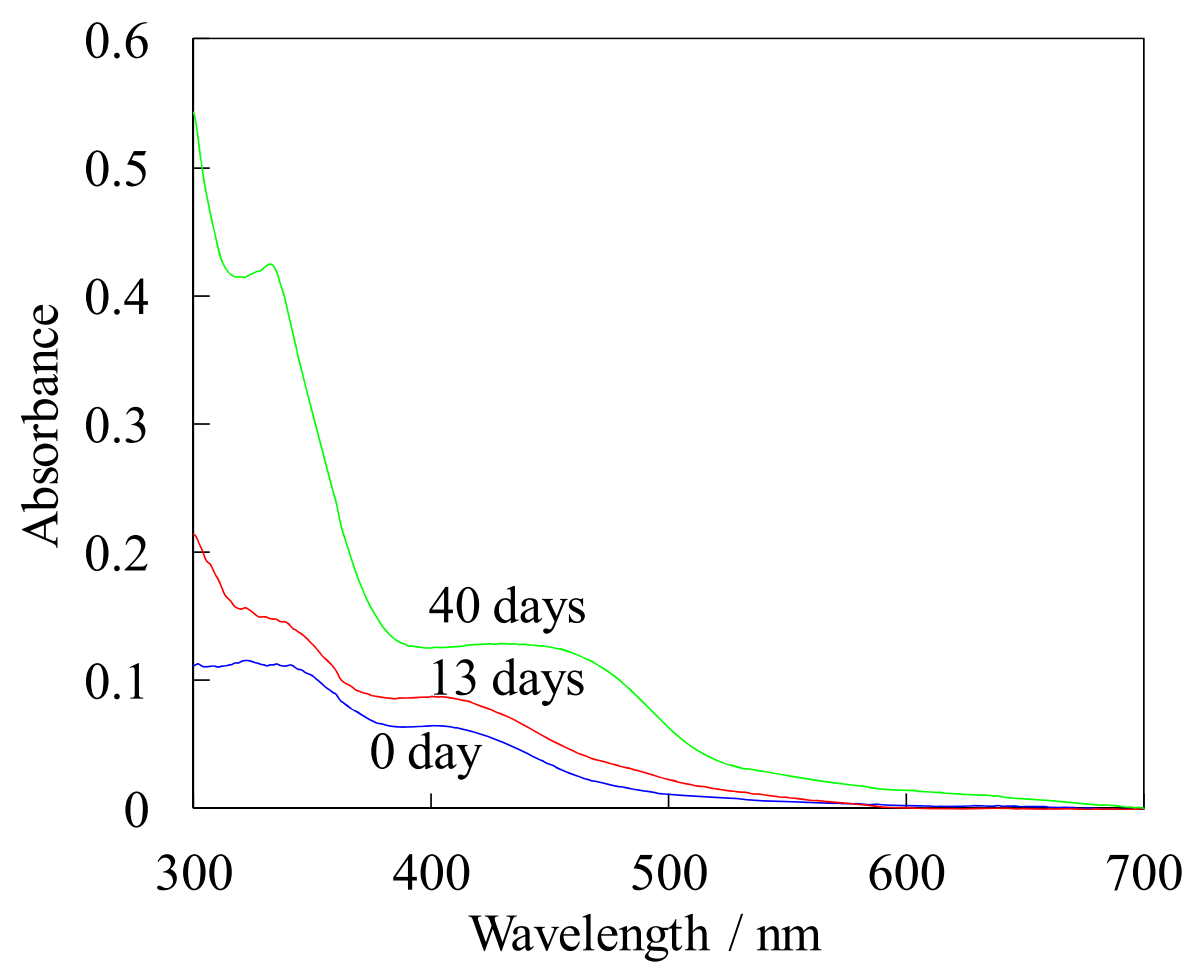

(b) 


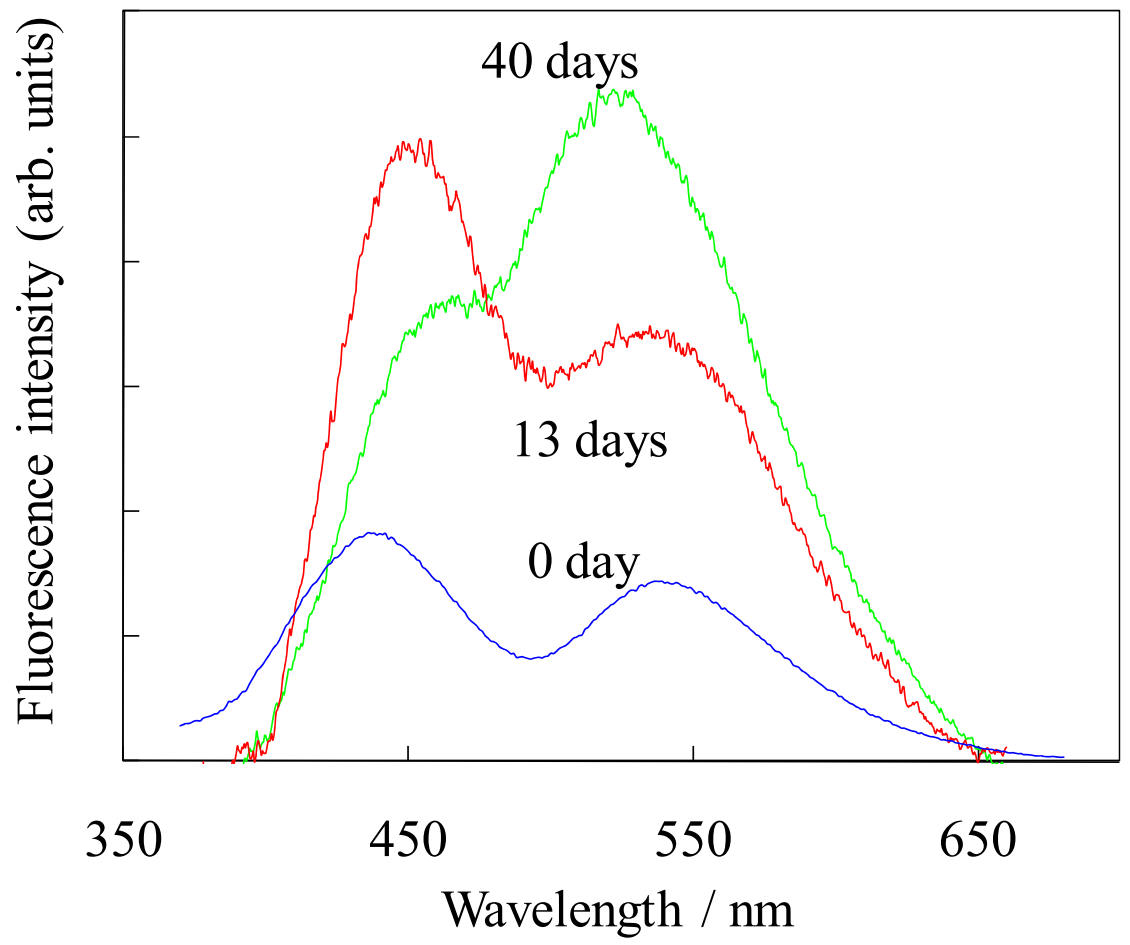


Figure 2

(a)

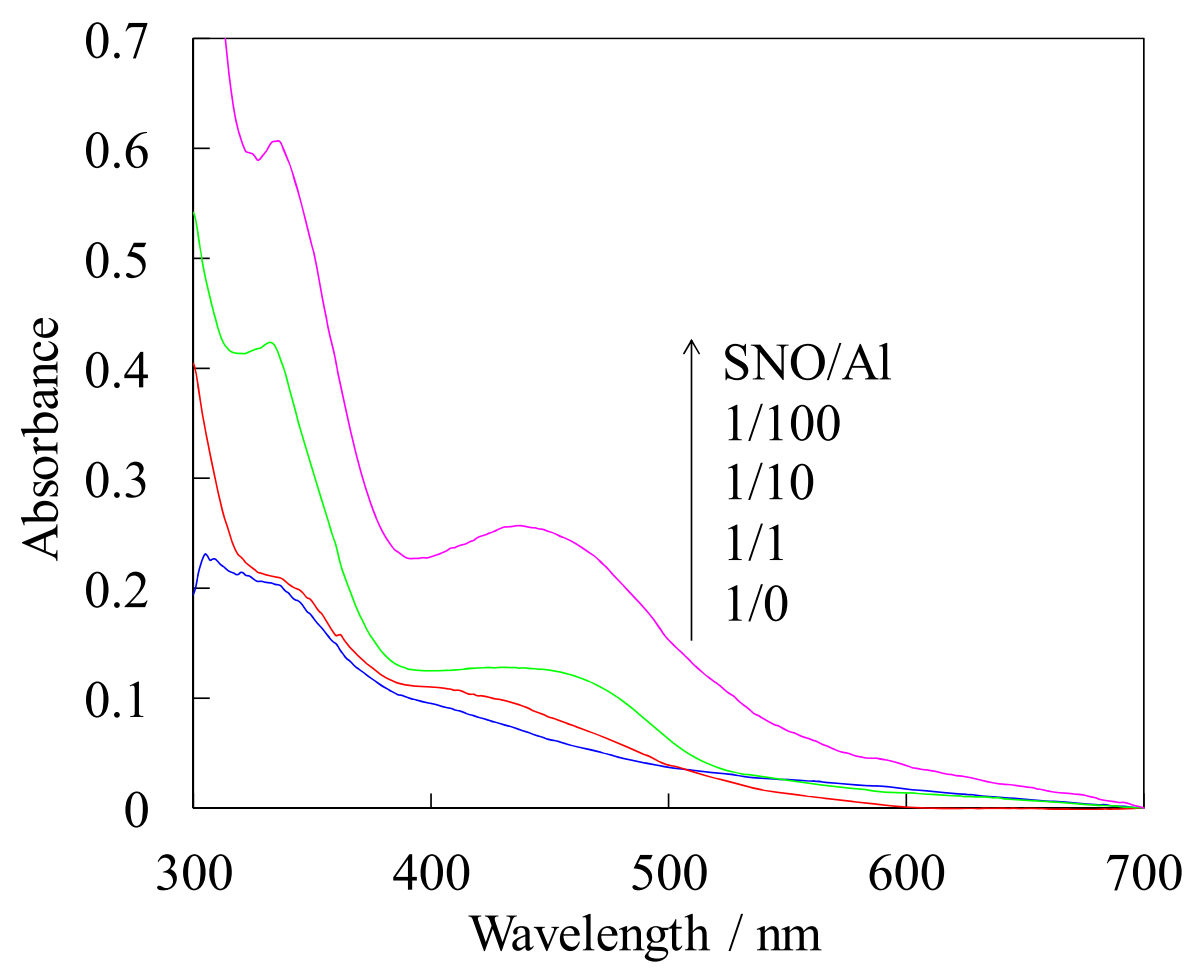

(b) 


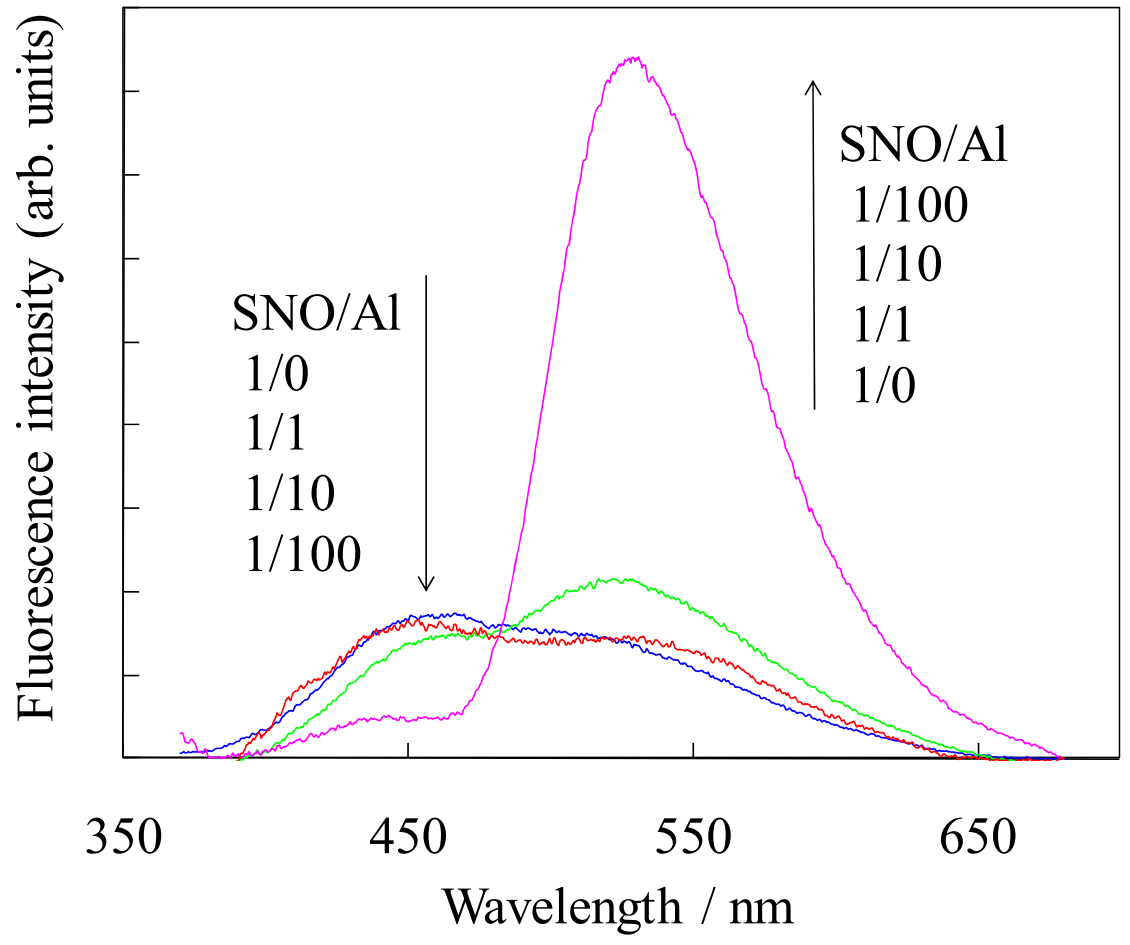


Figure 3

(a)

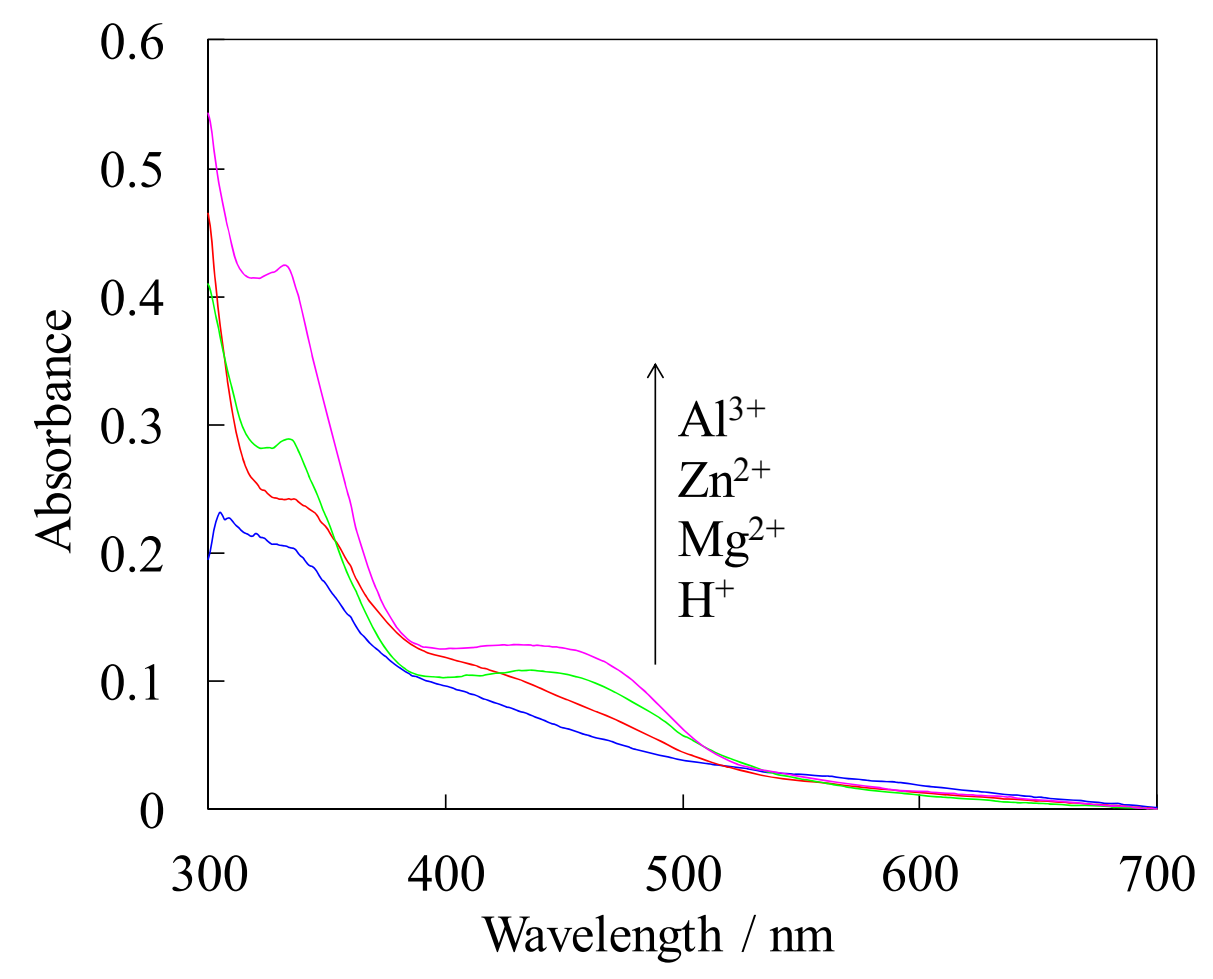

(b) 


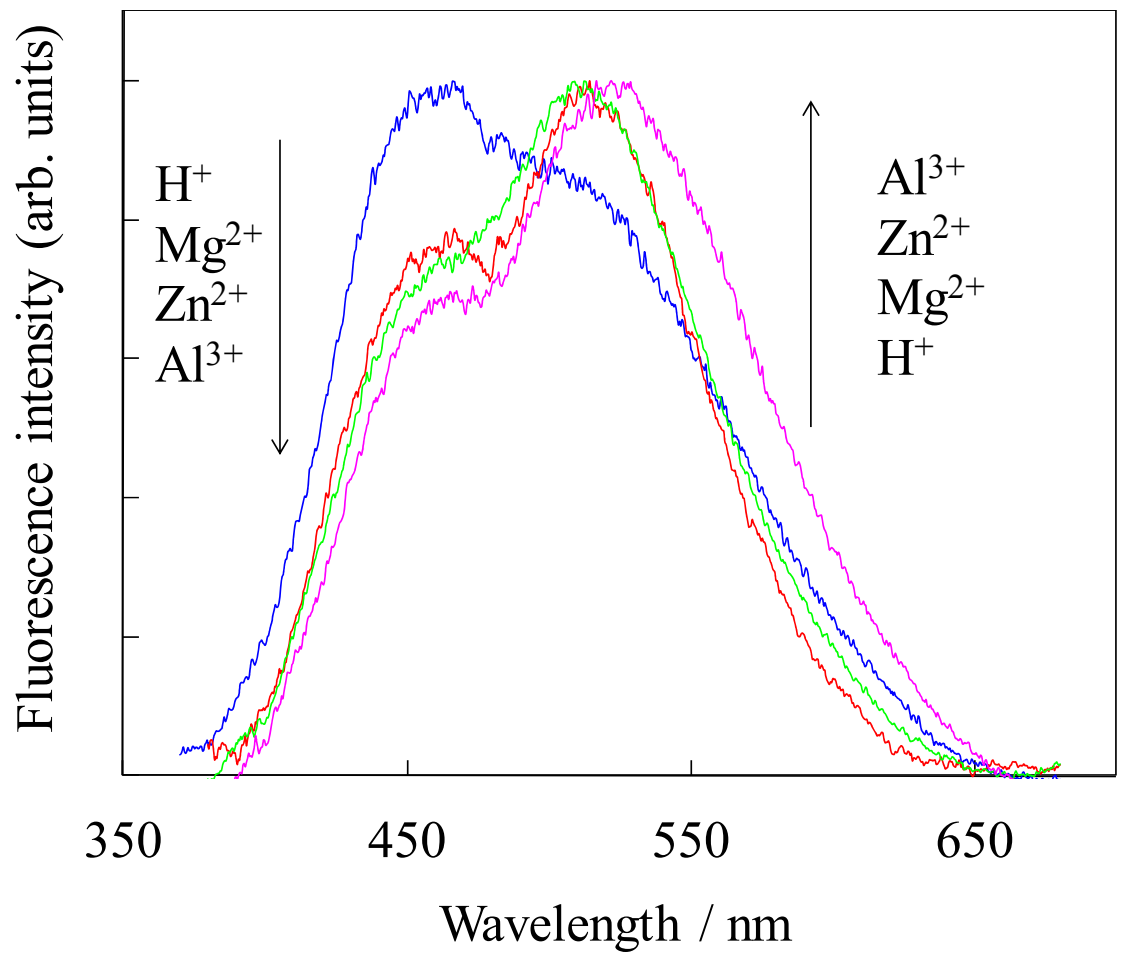


Figure 4
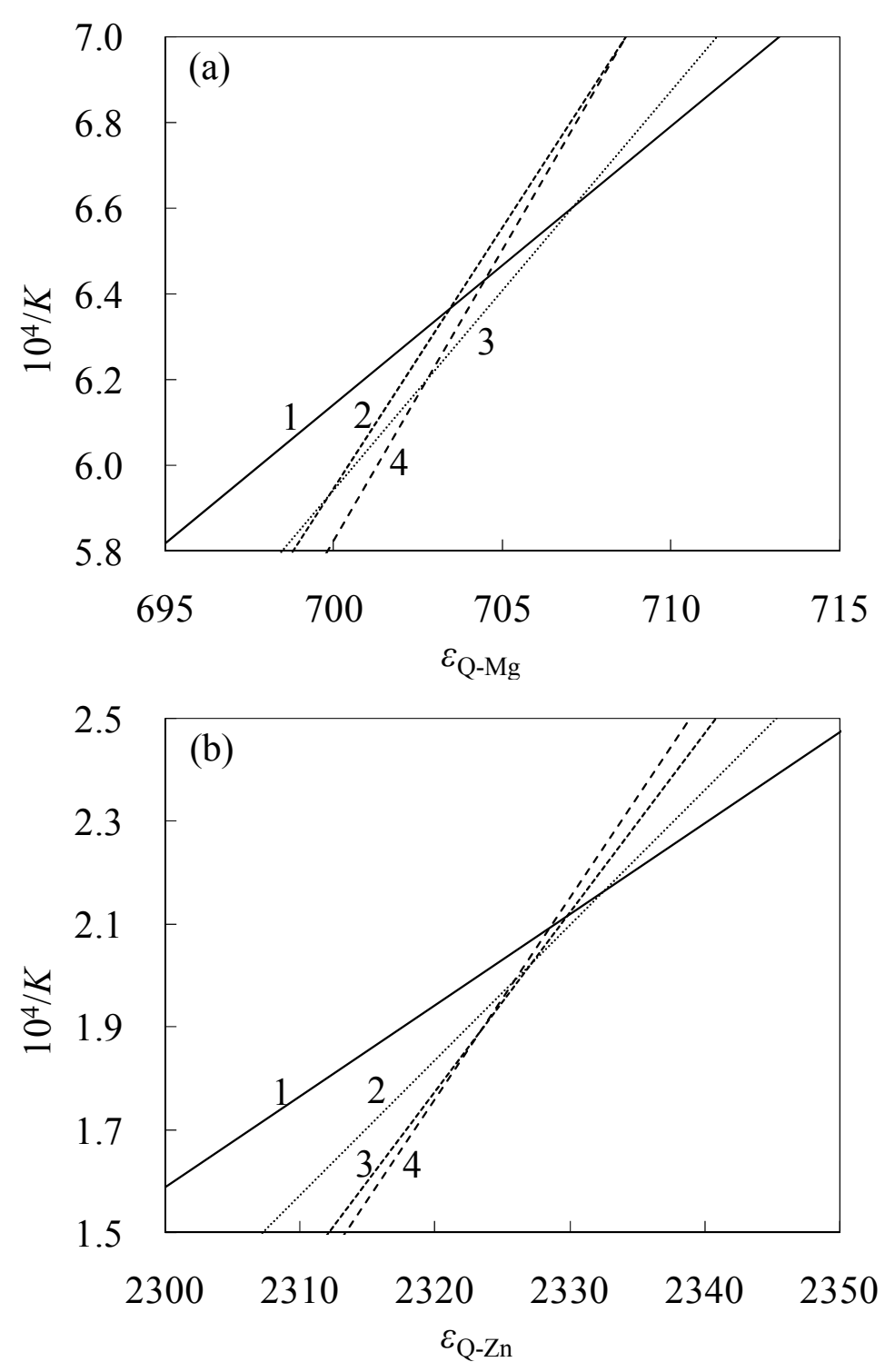


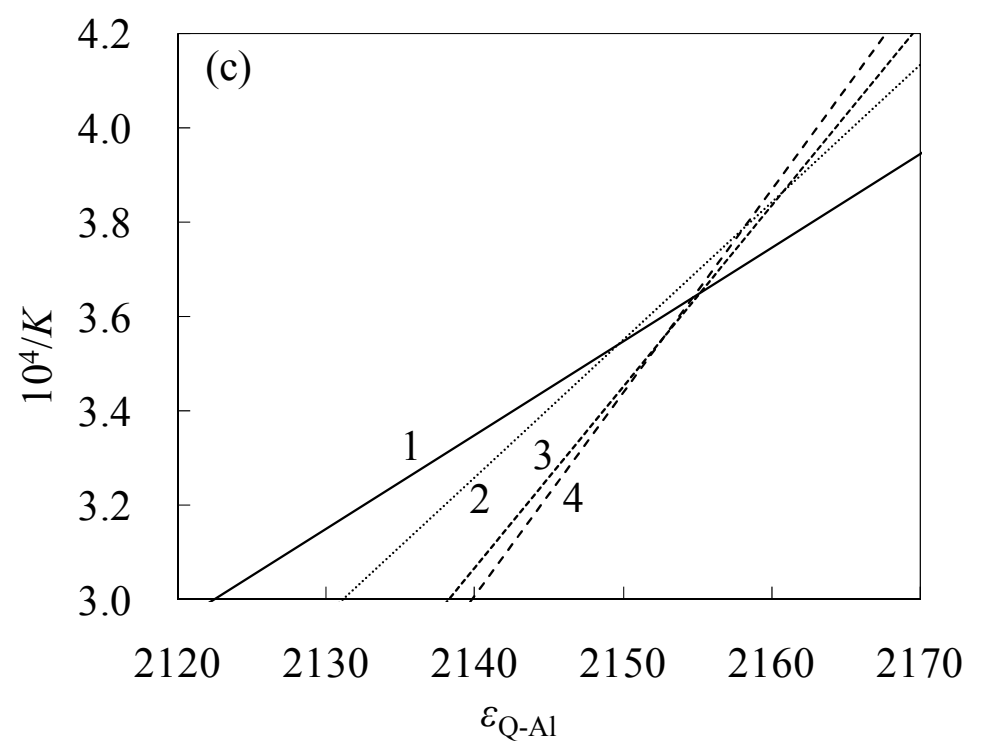


Figure 5

(a)

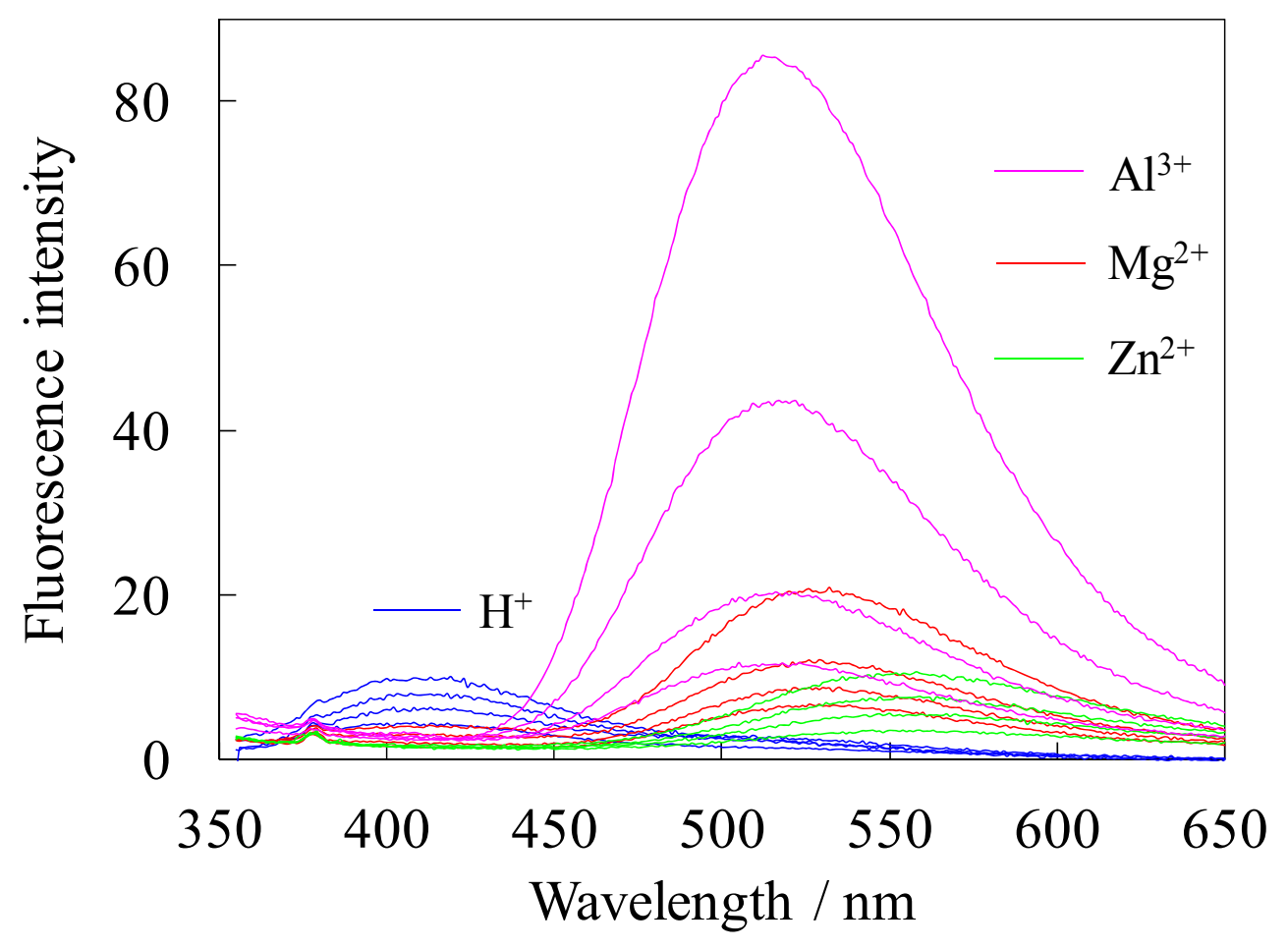

(b) 


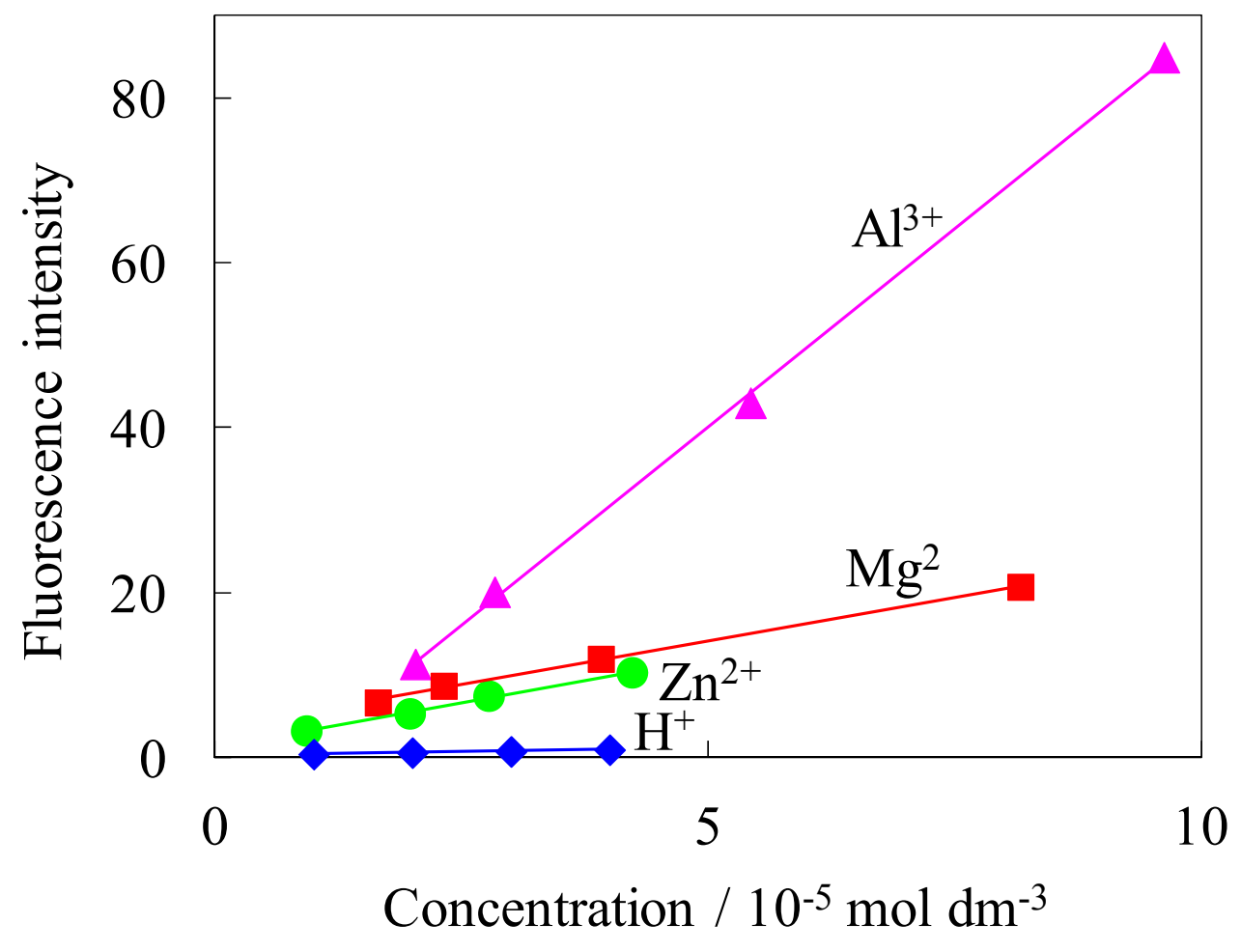


Figure 6

(a)

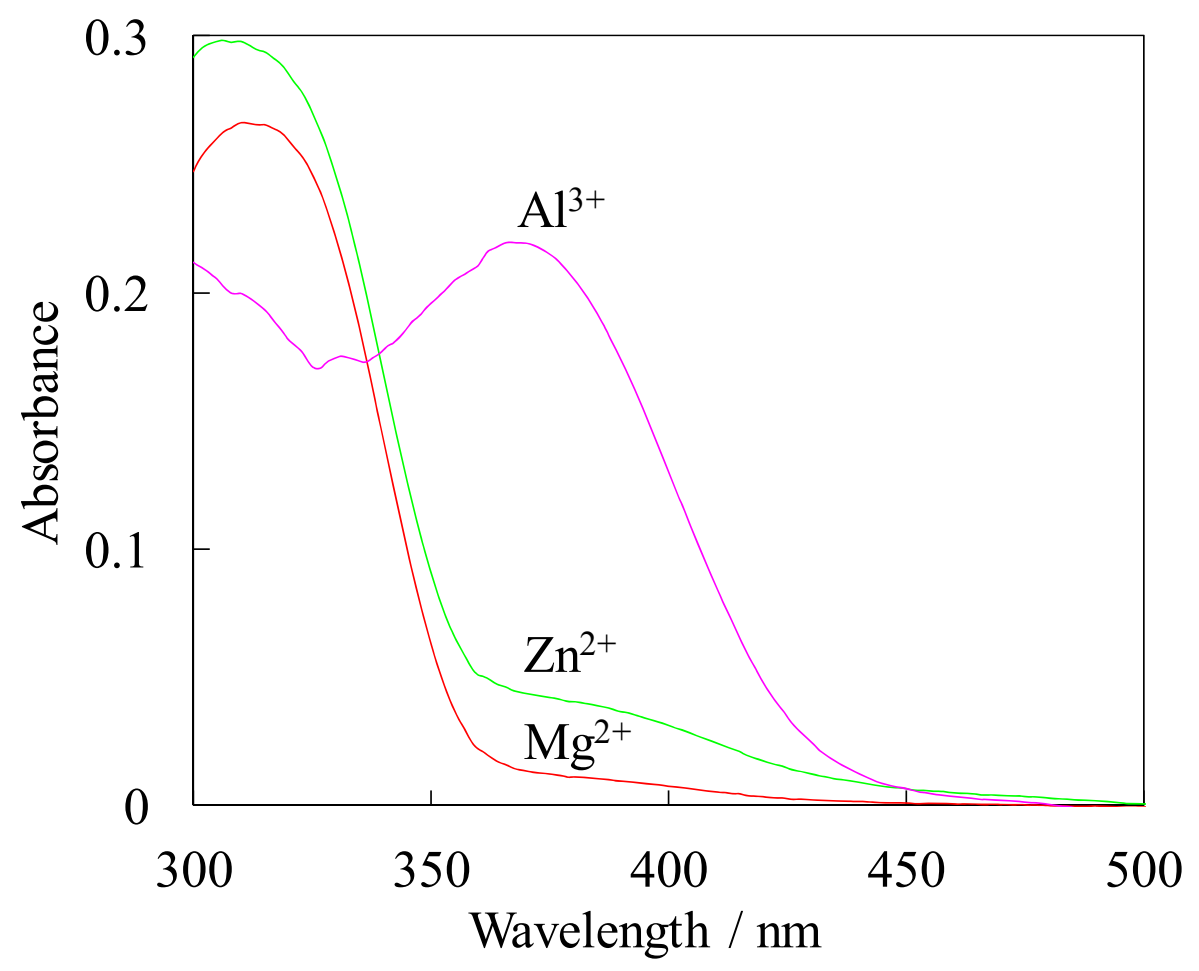

(b) 


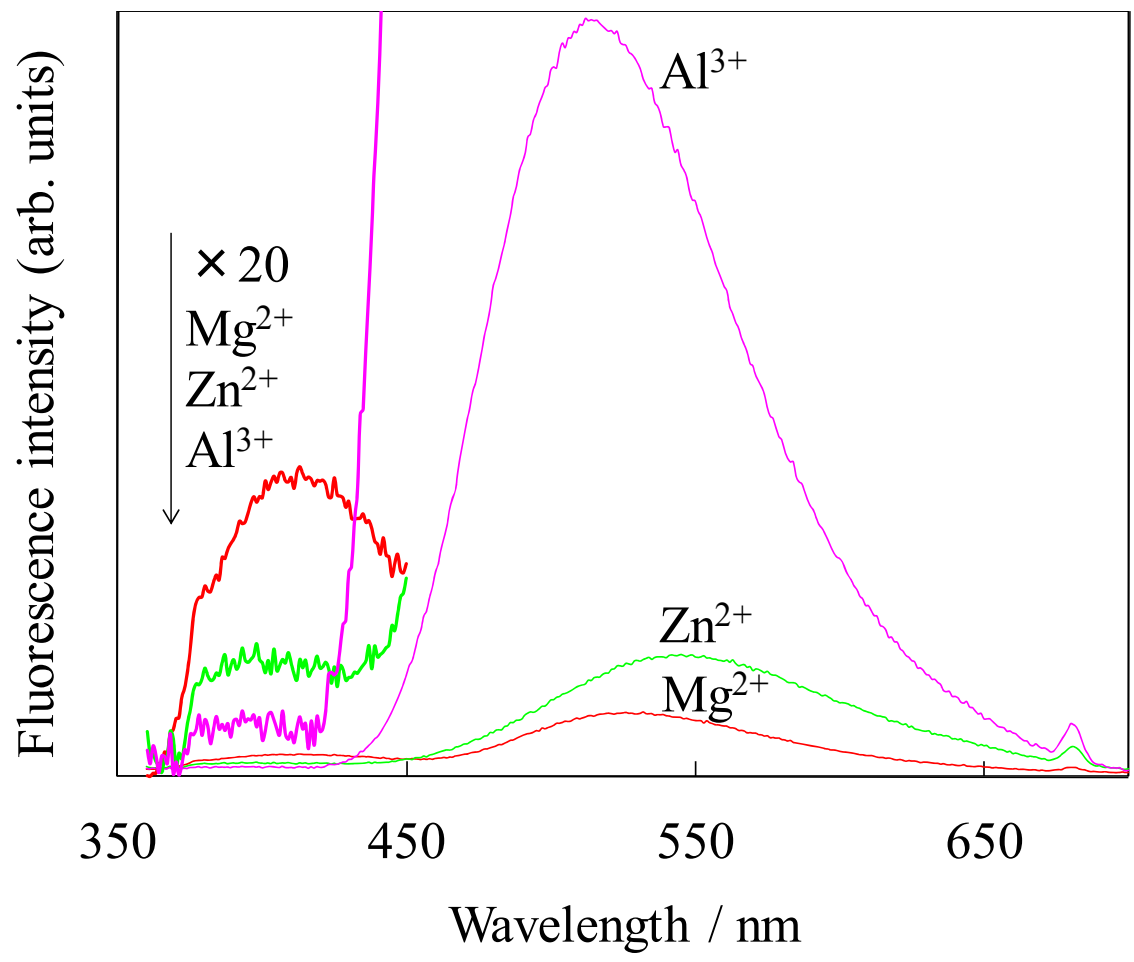


Figure 7

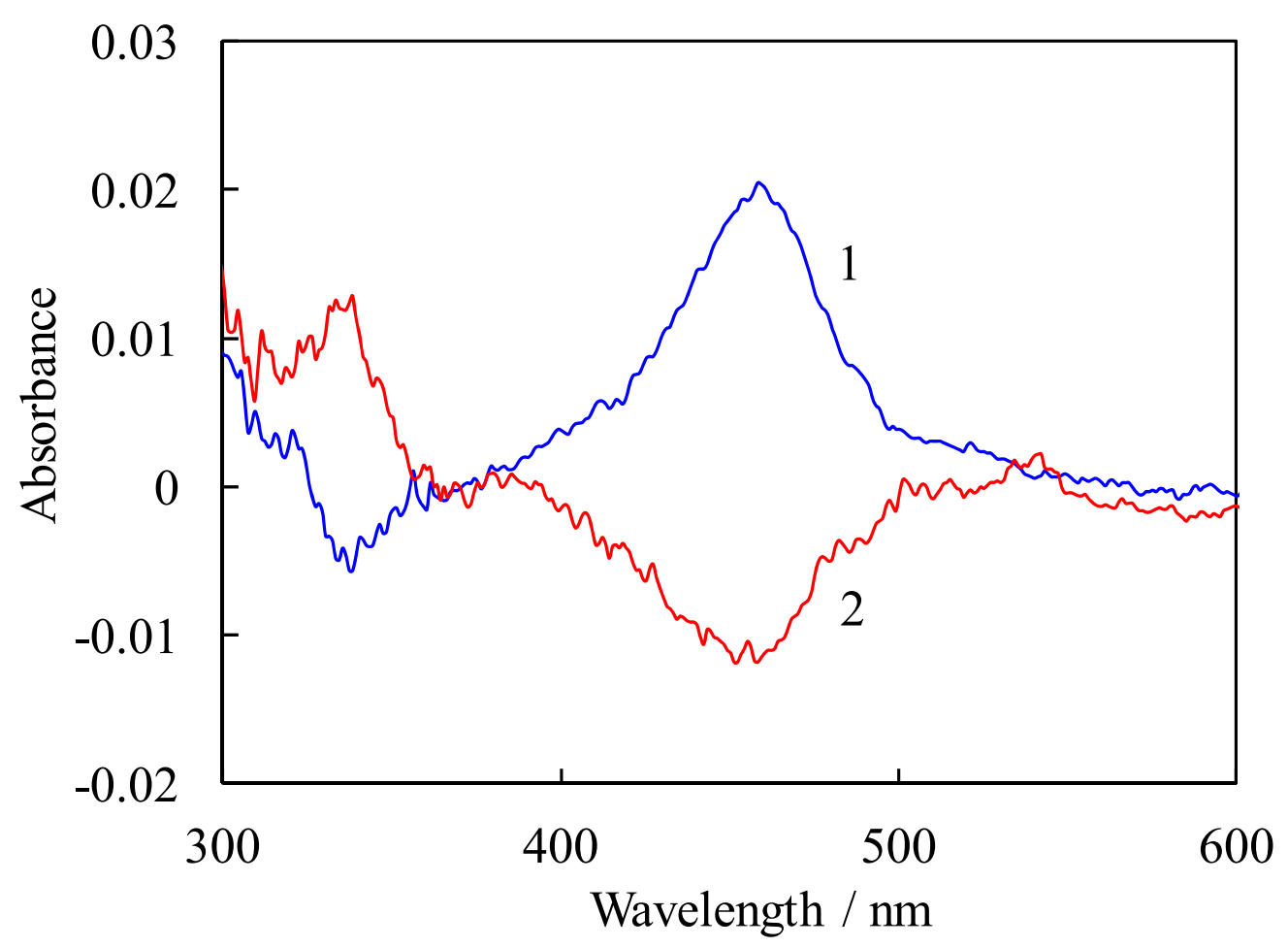


Figure 8
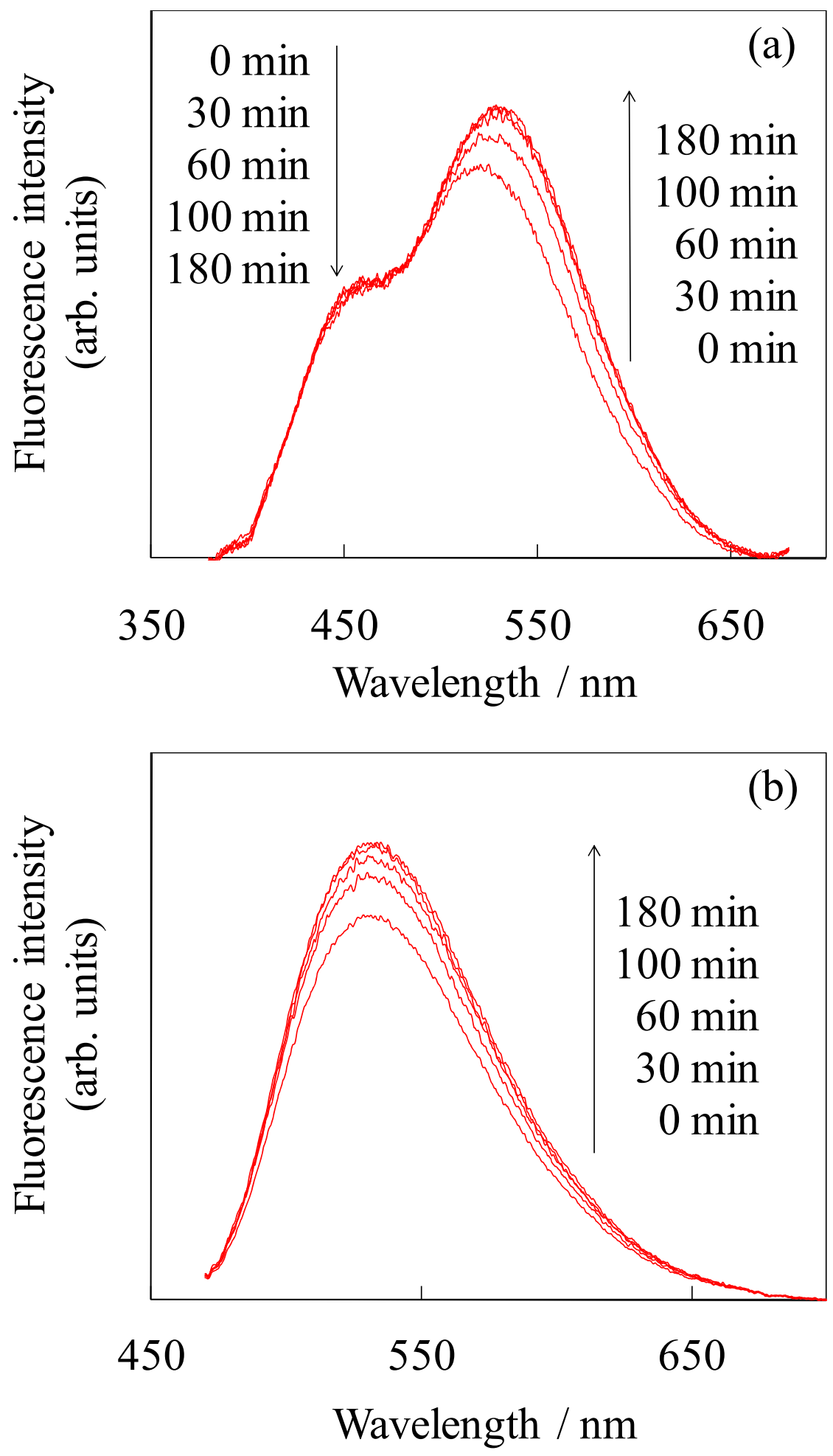
Figure 9
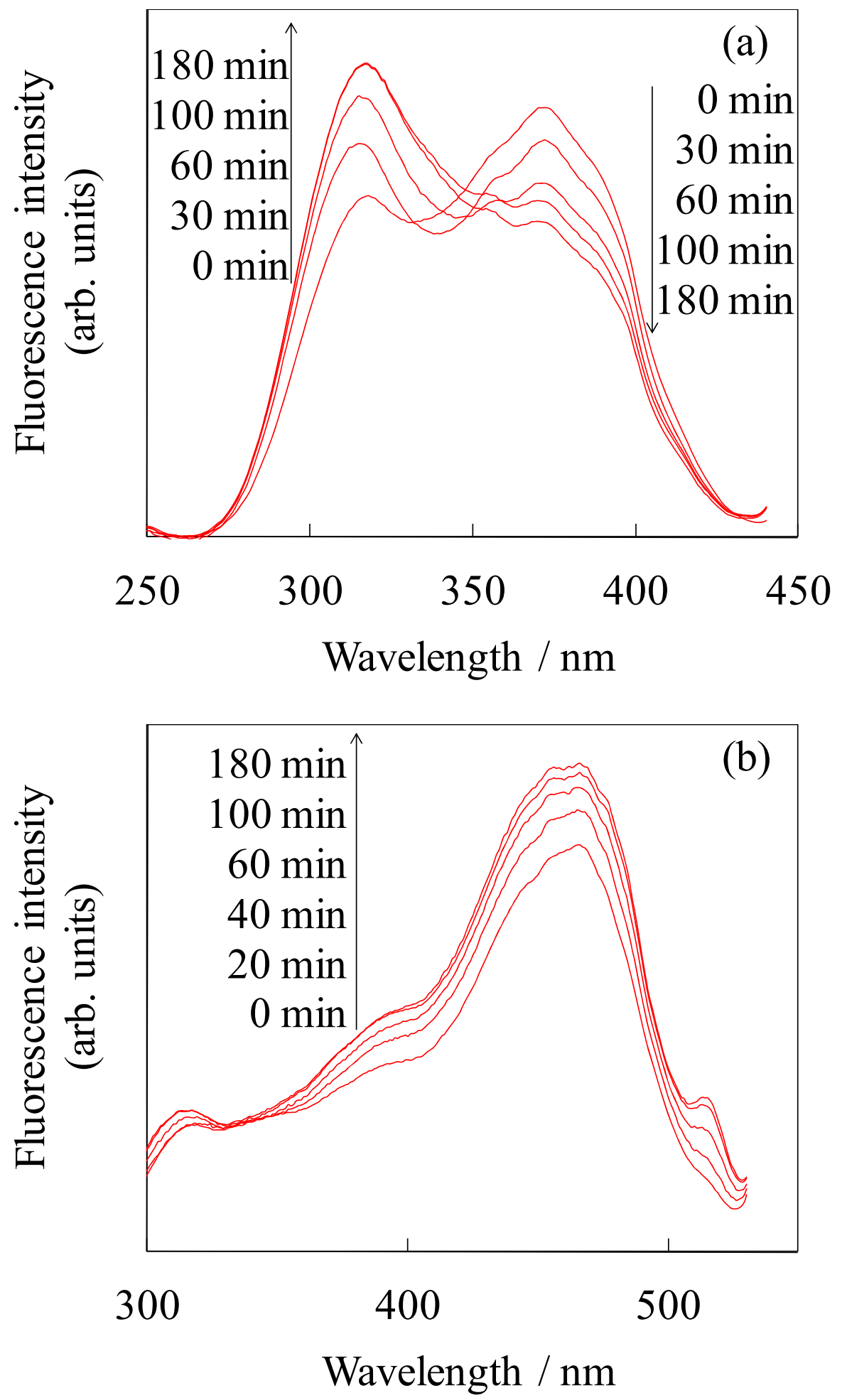
Figure 10
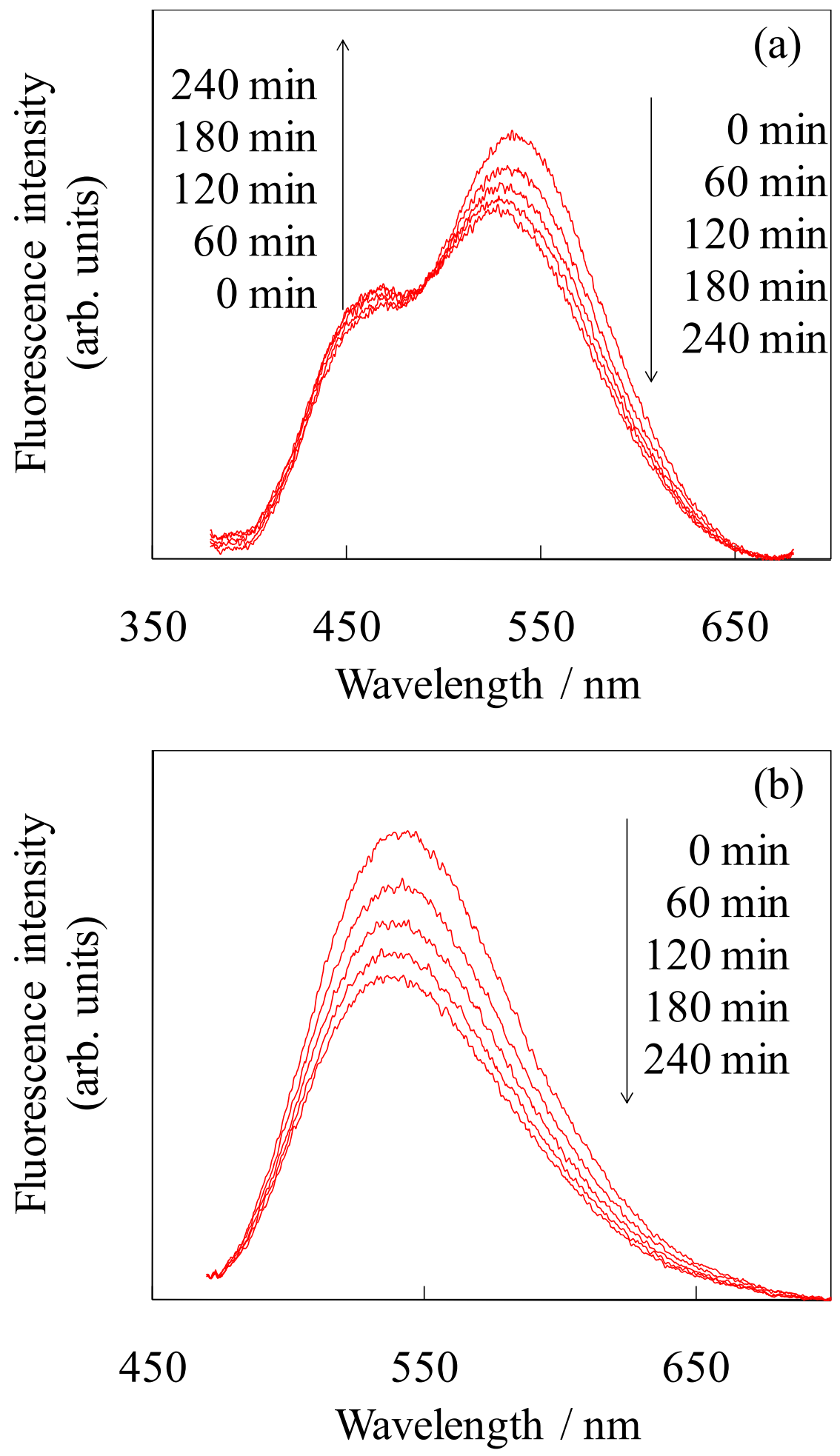
Figure 11
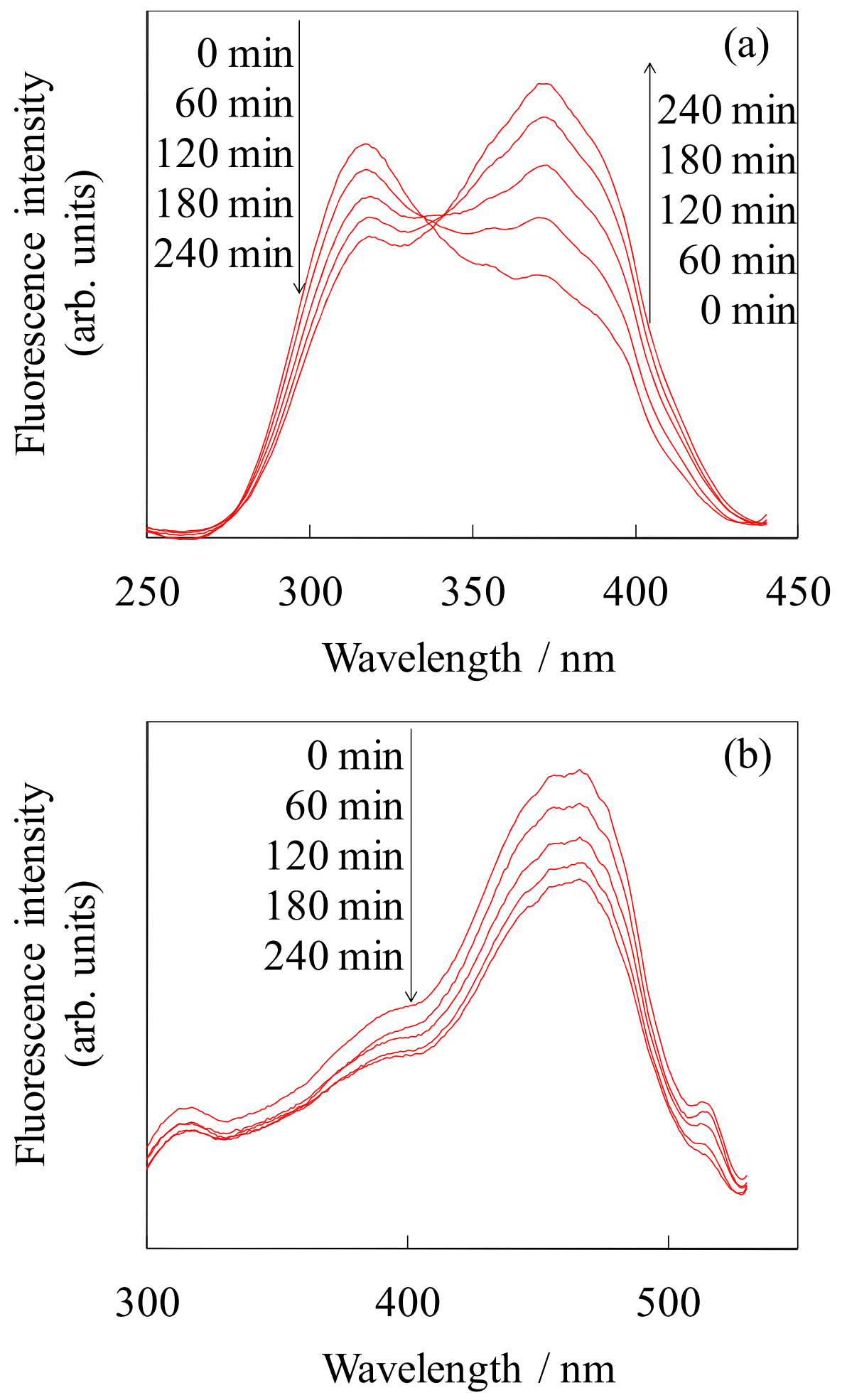
Figure 12
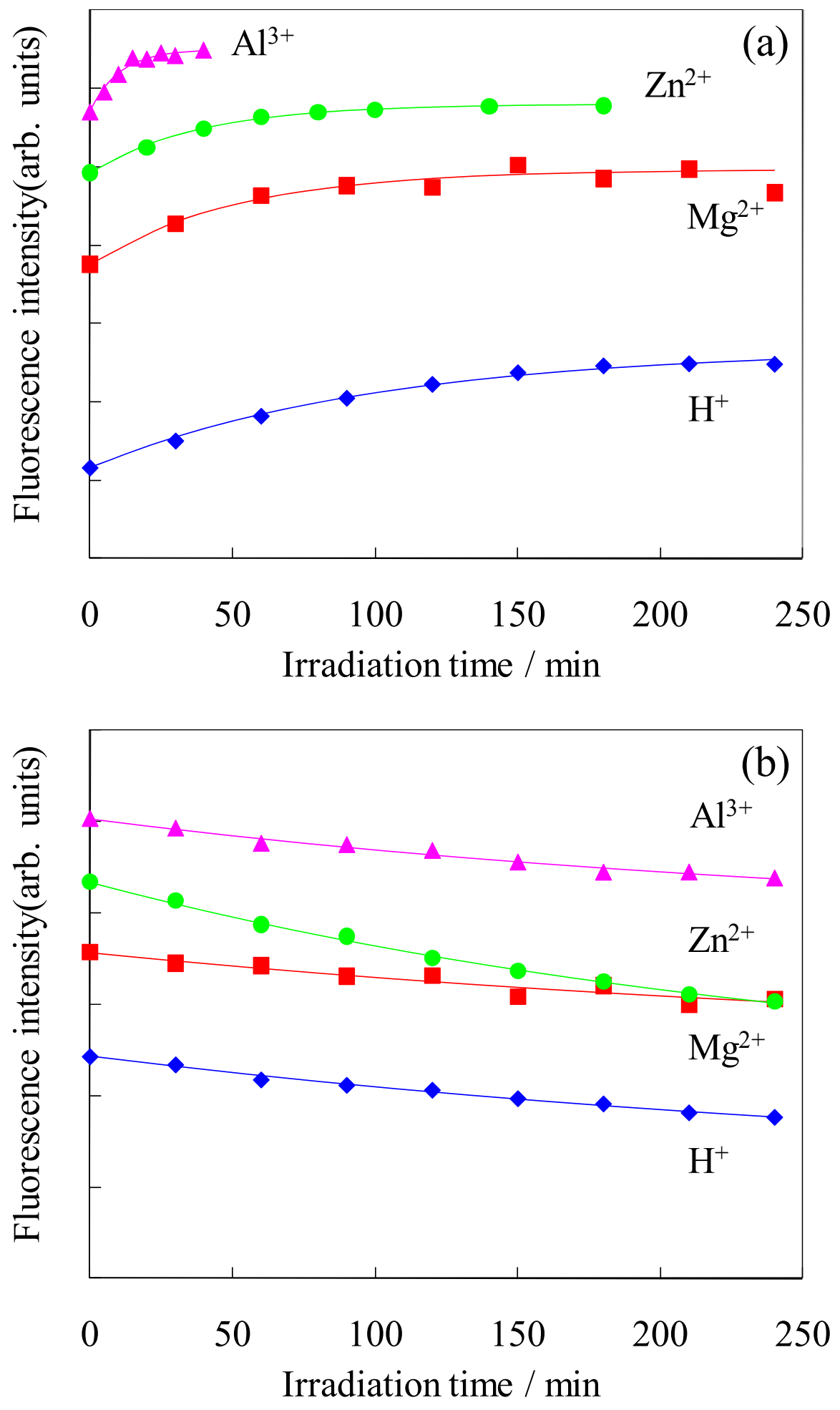


\section{Supporting information}

\section{Figure S1}

UV-vis absorption spectra of 8-HQ ethanol solutions with (a) $\mathrm{Mg}^{2+}$, (b) $\mathrm{Zn}^{2+}$, and (c) $\mathrm{Al}^{3+}$ in which the concentration of 8 -HQ was $1.0 \times 10^{-4} \mathrm{~mol} \mathrm{dm}^{-3}$ and those of metal ions were (1) 0 , (2) $4.0 \times 10^{-3}$, (3) $6.0 \times 10^{-3}$, (4) $8.0 \times 10^{-3}$, and (5) $9.0 \times 10^{-3} \mathrm{~mol} \mathrm{dm}^{-3}$. The ratio of $\mathrm{Q}^{-}$to the metal ion should be $1 / 1$ under these conditions because the metal concentrations were much higher than that of 8-HQ.

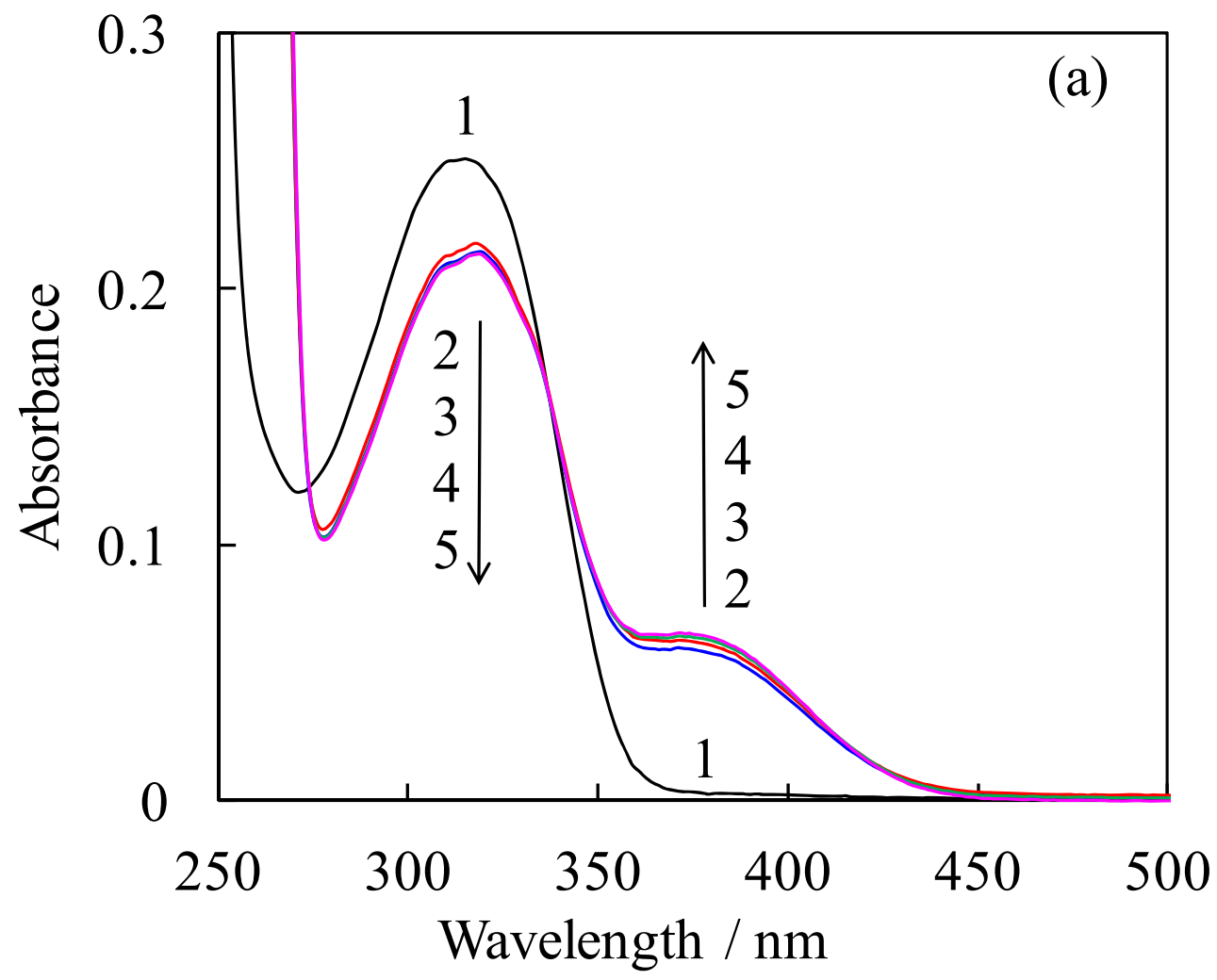



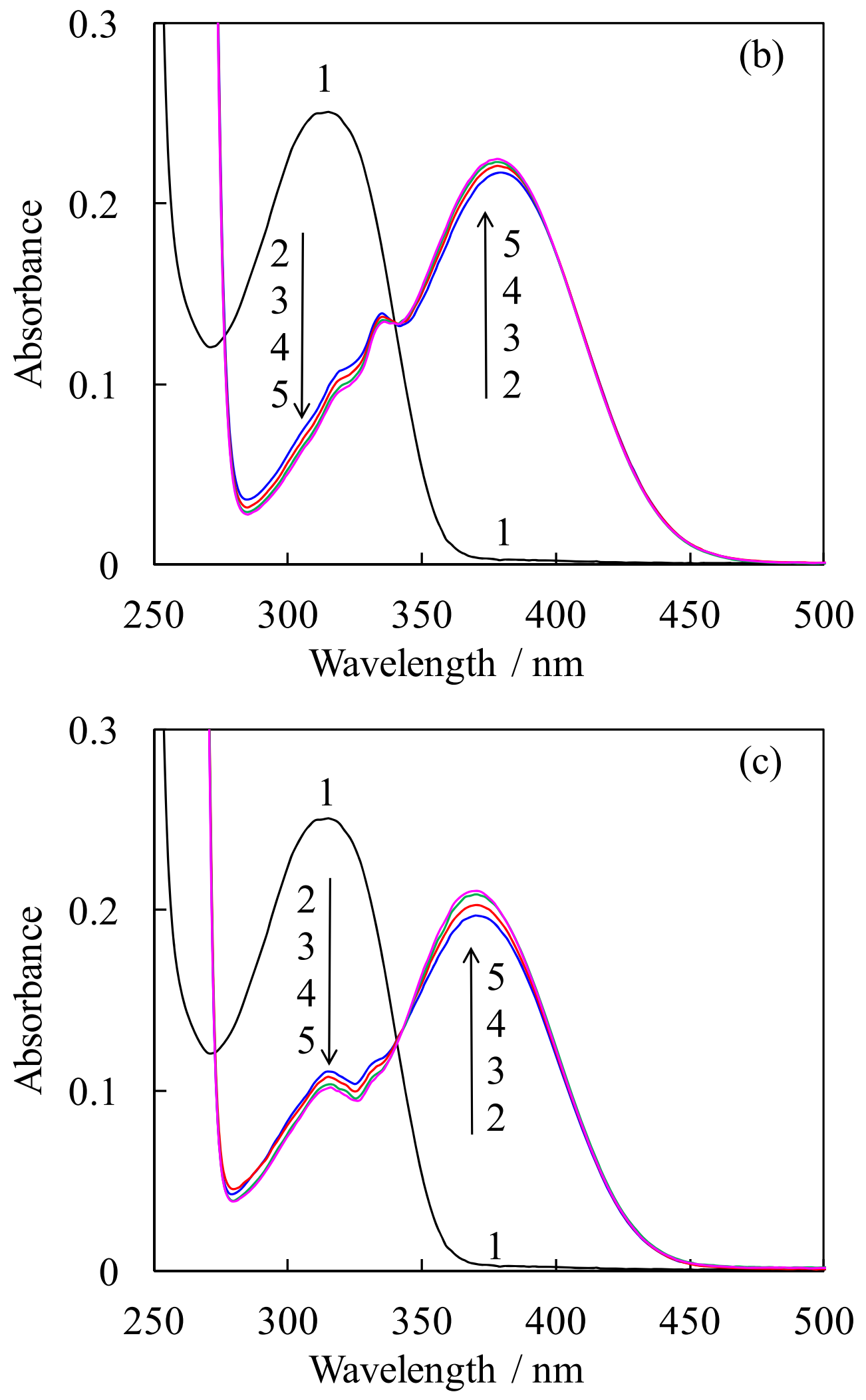


\section{Figure S2}

Fluorescence spectra of the silica xerogels containing 8-HQ with $\mathrm{Mg}^{2+}, \mathrm{Zn}^{2+}$, and $\mathrm{Al}^{3+}$. The excitation wavelengths were (a) 320 and (b) $370 \mathrm{~nm}$. Upon $320 \mathrm{~nm}$ excitation, the fluorescence intensity of $\mathrm{Q}^{-}-\mathrm{Al}^{3+}$ was higher than those of $\mathrm{Q}^{-}-\mathrm{Zn}^{2+}$ and $\mathrm{Q}^{-}-\mathrm{Mg}^{2+}$. The relative intensities of 8-HQ observed upon $320 \mathrm{~nm}$ excitation were higher than those observed upon $342 \mathrm{~nm}$ excitation, which was the isosbestic point. The fluorescence intensity of the complex was higher in order of $\mathrm{Al}^{3+}, \mathrm{Zn}^{2+}$, and $\mathrm{Mg}^{2+}$ upon $370 \mathrm{~nm}$ excitation. No fluorescence of 8-HQ was observed.

(a)

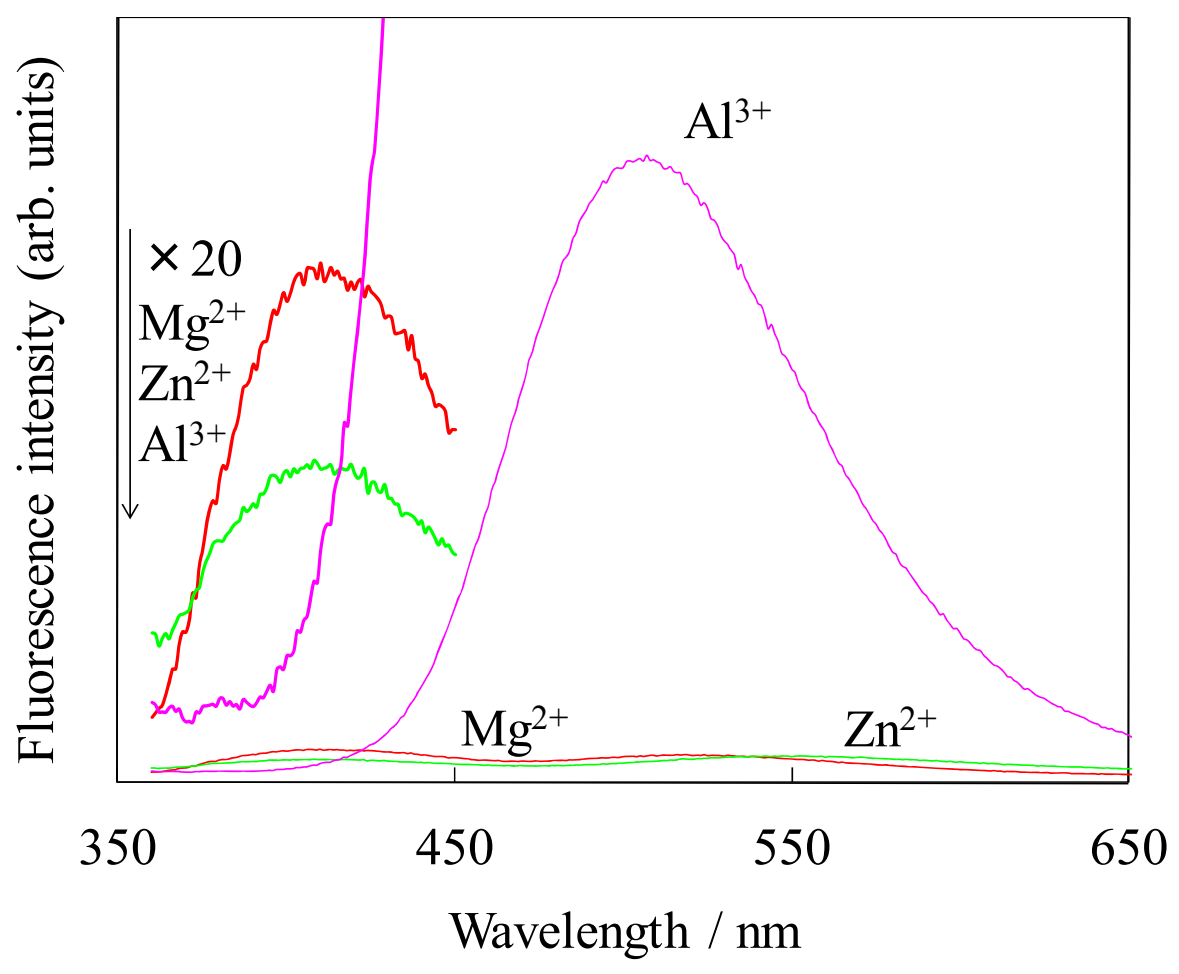


(b)

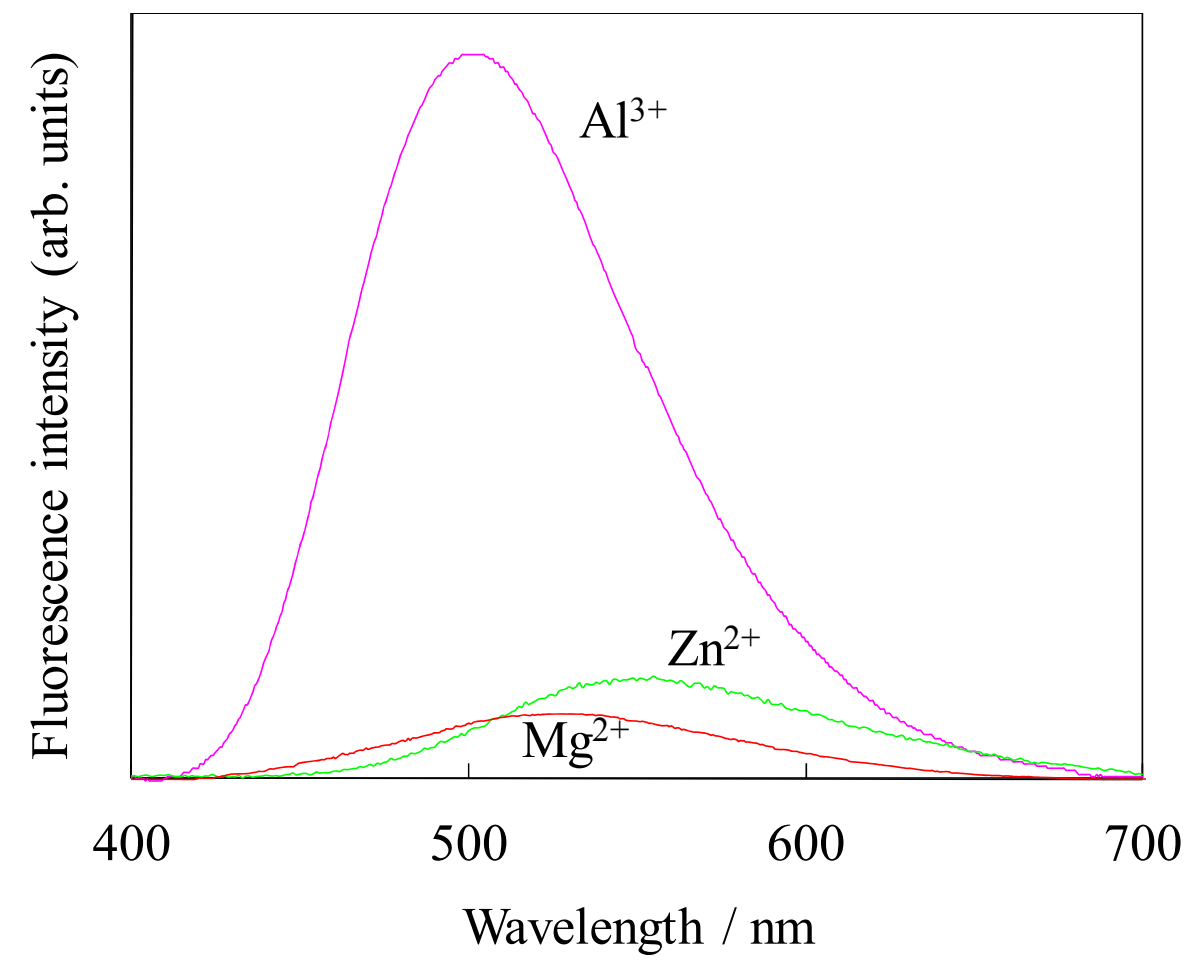

